\title{
Effect of Mn doping on structure, the dielectric and electric properties of BCZT ceramics
}

\section{Khmiri Ismail ( $\nabla$ khmiriismail505@yahoo.fr)}

faculty of science of sfax

\section{Issa KRIAA}

Faculty of Sciences of Sfax: Universite de Sfax Faculte des Sciences de Sfax

\section{Hamadi KHEMAKHEM}

Faculté des Sciences de Sfax: Universite de Sfax Faculte des Sciences de Sfax

\section{Research Article}

Keywords: dielectric, ceramic, ferroelectric, permittivity

Posted Date: March 30th, 2021

DOl: https://doi.org/10.21203/rs.3.rs-294800/v1

License: (1) This work is licensed under a Creative Commons Attribution 4.0 International License. Read Full License

Version of Record: A version of this preprint was published at Applied Physics A on March 26th, 2021. See the published version at https://doi.org/10.1007/s00339-021-04412-0. 


\title{
Effect of Mn doping on structure, the dielectric and electric
}

\section{properties of BCZT ceramics}

\author{
Ismail KHMIRI*, Issa KRIAA, Hamadi KHEMAKHEM \\ Laboratory of Multifunctional Materials and Applications (LaMMA), University of Sfax, \\ Faculty of Sciences of Sfax, Soukra road BP 1171, 3000 Sfax, Tunisia.
}

*Corresponding author: khmiriismail505@yahoo.fr

\begin{abstract}
:
The synthesis of $(\mathrm{Ba} 0.99 \mathrm{Ca} 0.01)\left(\mathrm{Zr}_{0.2} \mathrm{Ti}_{0.8}\right) \mathrm{O}_{3}(\mathrm{BCZT})$ and doped $\left(\mathrm{Ba} 0.99 \mathrm{Ca}_{0.01}\right)\left(\mathrm{Zr}_{0.2} \mathrm{Ti}_{0.8-}\right.$ $\left.{ }_{x} \mathrm{Mn}_{\mathrm{x}}\right) \mathrm{O}_{3}(\mathrm{BCZT}-\mathrm{xMn})$ ceramics was successfully carried out by the solid-state method. The doping effect is followed by X-ray powder diffraction, scanning electron microscopy (SEM), and dielectric and conductivity measurements. Indeed, X-ray diffraction measurements show the crystalline structure of ceramics. SEM images indicate the doping effect on the studied perovskite microstructure. The results indicate that during doping the maximum value of the temperature $(\mathrm{Tm})$ of the dielectric constant varies slightly, and there will be a considerable decrease in permittivity, dielectric losses and conductivity. Manganese ions are well integrated in the perovskite while maintaining the solid solution.
\end{abstract}

Keywords: dielectric, ceramic, ferroelectric, permittivity. 


\section{Introduction}

Since the 1950s, the $\mathrm{Pb}$ based ceramic perovskite compositions like $\mathrm{Pb}\left(\mathrm{Zr}_{1-\mathrm{x}} \mathrm{Ti}_{\mathrm{x}}\right) \mathrm{O}_{3}$ (PZT) and $\mathrm{PbMg}_{1 / 3} \mathrm{Nb}_{2 / 3} \mathrm{O}_{3}(\mathrm{PMN})$ have been frequently used worldwide for their dielectric properties $[1,2]$. This material has a very high dielectric permittivity at the Curie temperature and a coupling coefficient too. For this reason, it is found useful in various fields of applications such as transducers and sensors [3-5]. However, these lead oxides have recently been found to be toxic and seriously dangerous to the environment and human health. Much research has therefore been conducted to find its lead-free alternative with similar ferroelectric and piezoelectric effects, generally titanium-based solid solutions such as $\mathrm{Bi}_{0.5} \mathrm{Na}_{0.5} \mathrm{TiO}_{3}(\mathrm{NBT}), \mathrm{K}_{0.5} \mathrm{Na}_{0.5} \mathrm{NbO}_{3}(\mathrm{KNN}), \mathrm{BaTiO} 3(\mathrm{BT})$ and $(\mathrm{Ba}, \mathrm{Ca})(\mathrm{Ti}, \mathrm{Zr}) \mathrm{O}_{3}(\mathrm{BCTZ})$ [6]. Among piezoelectric materials, we can mention the most famous one, (1-x) $\mathrm{Ba}\left(\mathrm{Zr}_{0.2 \mathrm{Ti} 0.8}\right) \mathrm{O}_{3}-\mathrm{x}(\mathrm{Ba} 0.7 \mathrm{Ca} 0.3) \mathrm{TiO}_{3}(\mathrm{BZT}-\mathrm{xBCT})$, a pseudo-binary system that had a very high piezoelectric coefficient of about $600 \mathrm{pc} / \mathrm{N}$ at room temperature, an amazing value that even exceeds that of the PZT perovskites [7-10].

Among the important characteristics of this pseudo-binary ferroelectric BCZT is the existence of a triple point in the previously studied BZT-BCT diagram, located at $\mathrm{x}=0.32$ where this region is considered as a separation between the rhombohedral and the tetragonal symmetry and corresponds to a high permittivity and huge electromechanical coefficients[11].

In fact, at the end of the last century, Simon et al focused their researche on the ternary form $\mathrm{BaTiO}_{3}-\mathrm{CaTiO}_{3}-\mathrm{BaZrO}_{3}$, which led to a diagram of four zones with different structures and dielectric aspects $[2,12]$, as shown in figure 1:

Zone 1: Dielectric behavior similar to $\mathrm{BaTiO}_{3}$ in both its proximity and the $\mathrm{Ba}_{1-\mathrm{x}} \mathrm{Ca}_{\mathrm{x}} \mathrm{TiO}_{3}$ (BT-CT), with three anomalies corresponding to rhombohedral (R), tetragonal (T), orthorhombic $(\mathrm{O})$ and cubic $(\mathrm{C})$ transitions. 
R-O transition temperature decreases remarkably as the substitution of $\mathrm{Ba}^{2+}$ by $\mathrm{Ca}^{2+}$ increases in perovskite A sites.

Zone 2: For solid compositions close to $\mathrm{BaTi}_{1-\mathrm{x}} \mathrm{Zr}_{\mathrm{x}} \mathrm{O}_{3}$ with $0.1<\mathrm{x}<0.27$, only one dielectric anomaly is detected related to the $\mathrm{R}-\mathrm{C}$ transition, the Curie temperature peak is remarkable without dispersion by frequency effect.

Zone 3: In $\mathrm{BaTi}_{1-\mathrm{x}} \mathrm{Zr}_{\mathrm{x}} \mathrm{O}_{3}$ proximity with $0.275<\mathrm{x}<0.42$, there is a larger peak with higher temperature values and a frequency dispersion. At the macroscopic scale, the compositions keep their shape and polarization regardless of the temperature.

Zone 4: This region separates zone II from zone III where, depending on the composition, classic ferroelectric states and relaxing states coexist.

However, the formation of the pure perovskite phase BCZT requires a very high calcinations and sintering temperature of about $1420^{\circ} \mathrm{C}$ for sintering. The studies carried out by the researchers aim at reducing the temperature and improving the electrical presets of the perovskite.

The doping with various metal ions such as $\mathrm{Ca}^{2+}[13], \mathrm{Cu}^{2+}[14], \mathrm{Fe}^{3+}[14], \mathrm{Bi}^{3+}[11]$, $\mathrm{Mg}^{2+}$ [14] and $\mathrm{Mn}^{4+}$ [15] either in site $\mathrm{A}$ or/and $\mathrm{B}$ can improve the properties of BCZT ceramics. As mentioned, the addition of a dopant to (BCZT) ceramics can improve densification, dielectric and ferroelectric properties. $\mathrm{MnO}_{2}$ is an interesting additive because of its multivalence which can be a donor or acceptor dopant [16]. Research studies show that the addition of Mn can reduce dielectric losses and increase the densification of dielectric metals [5].

Mn doping at $\mathrm{B}$ sites of the perovskite $(\mathrm{Ba} 0.99 \mathrm{Ca} 0.01)\left(\mathrm{Zr}_{0.2} \mathrm{Ti}_{0.8-\mathrm{x}} \mathrm{Mn}_{\mathrm{x}}\right) \mathrm{O}_{3}(\mathrm{BCZT}-\mathrm{xMn})$ structure creates a variety of compositions with many properties similar to those of lead ceramics, such as cooling devices and dielectric responses enhanced by the rhombohedral $(\mathrm{R})$ and tetragonal (T) phases separated by an intermediate orthorhombic $(\mathrm{O})$ phase. 


\section{Experiment details:}

The lead-free BCZT-xMn ceramics were prepared by a solid state method where $\% \mathrm{x}=(0$, $0.25,1)$. The starting materials with highly-pure $(99.9 \%)$ powders $\mathrm{BaCO}_{3}, \mathrm{CaCO}_{3}, \mathrm{ZrO}_{2}, \mathrm{TiO}_{2}$ and $\mathrm{MnO}_{2}$, were dried in an oven heated to $150^{\circ} \mathrm{C}$ for one hour. Then, they were then weighed to obtain a mixture with stoichiometric proportions.

The mixture was milled for 2 hours, then pressed (100MPa) into a cylindrical shape and followed by calcinations at $1150^{\circ} \mathrm{C}$ for 15 hours. The resulting pellet was grounded again into powder for 2 hours to increase reactivity and reduce particle thickness to the micrometer. Subsequently, the powders obtained were reformed into pellets with a diameter of $8 \mathrm{~mm}$ and reheated at $1420^{\circ} \mathrm{C}$ for 4 hours.

The phase purity of the prepared ceramic was confirmed by X-ray powder diffraction (Philips X'Pert, PRO. X-RAY Diffractometer) using CuK $\alpha$ radiation $\left(\lambda=1.5418 \mathrm{~A}^{\circ}\right)$. The evolution of grain size is observed by the SEM technique using a scanning electron microscope. A precision impedance analyzer shows the evolution of the dielectric permittivity in relation with the temperature.

\section{Results and discussions:}

\subsection{X-ray diffraction:}

Figure 2 depicts the X-ray diffraction of BCZT-xMn ceramics. Firstly, the diagram does not indicate the existence of other phases than the structured perovskite, which implies that the $\mathrm{Mn}^{4+}$ particles are well introduced into the unit cell of the perovskite in order to preserve the structure of the solid solution. The X-ray diagrams of the BCZT and BCZT-xMn ceramics reveal peak of diffraction at $45^{\circ}$, which is consistent with crystals (002) and (200), indicative of the tetragonal structure of BCZT ceramics. 
In addition, the diffraction peaks are slightly shifted towards the widest angle for a higher Mn concentration indicating the decrease of the ceramic system constant (BCZT-Mn), which is linked in particular to the presence of $\mathrm{Mn}^{4+}$ occupying the $\mathrm{B}$ sites. In fact, the ionic radius of $\mathrm{Mn}^{4+}\left(0.54 \mathrm{~A}^{\circ}\right)$ is smaller than that of $\mathrm{Ti}^{4+}\left(0.605 \mathrm{~A}^{\circ}\right)$ and $\mathrm{Zr}^{4+}\left(0.72 \mathrm{~A}^{\circ}\right)$.

On the other hand, the diffraction peaks of BCZT-xMn ceramics exhibit a full width at half maximum that increases with Mn concentration. This can be linked to the size of the ceramic grains (which decreases if the Mn content becomes higher).

The reticular planes of a crystal are defined by their Miller indices (hkl), or there is an interference of planes for the triplets $(\mathrm{h}, \mathrm{k}, \mathrm{l})$ in orthorhombic structure. The interreticular distance $\mathrm{d}_{\mathrm{hkl}}$ was related to the Miller indices by the following relationship $[17,18]$ :

$$
\frac{1}{d_{h k l}^{2}}=\frac{h^{2}}{a^{2}}+\frac{k^{2}}{b^{2}}+\frac{l^{2}}{c^{2}}
$$

with $d_{h k l}$ is calculated from the Bragg equation [17-20]:

$$
2 d_{h k l} \sin \theta=\mathrm{n} \lambda
$$

where $\mathrm{n}$ is the order of diffraction taken equal to one in general $(n=1), \lambda$ is the wavelength of $\mathrm{X}$-ray diffraction equal to $1.5418 \mathrm{~A}^{\circ}$

The calculation of the lattice parameters $a, b$ and $c$ are shown in table 1 . These results indicate that the addition of $\mathrm{Mn}$ induces a slight variation in the lattice parameters. Indeed, the ionic radius of $\mathrm{Mn}^{4+}\left(0.54 \mathrm{~A}^{\circ}\right)$ and $\mathrm{Mn}^{3+}\left(0.645 \mathrm{~A}^{\circ}\right)$ are close to the ionic radius of $\mathrm{Ti}^{4+}\left(0.605 \mathrm{~A}^{\circ}\right)$. However the radius of $\mathrm{Mn}^{2+}\left(0.83 \mathrm{~A}^{\circ}\right)$ is larger than that of $\mathrm{Ti}^{4+}$, and the occupation of the $\mathrm{Ti}$ site by Mn ions induces a weak deformation of the crystal lattice.

The calculation of the nanometric dimensions of the BCZT-xMn ceramic particles is based on the study of ray diffraction; the size of the crystallites is given by the following Scherer's law[18,21]:

$$
\mathrm{D}=\frac{K \lambda}{\beta \cos \theta}
$$


where $\mathrm{D}$ is the size of the crystallites, $\lambda$ is the wavelength of the $\mathrm{X}$-rays $\left(1.5418 \mathrm{~A}^{\circ}\right), \mathrm{K}$ is the Scherer constant taken equal to $0.9, \theta$ is the diffraction peak angle and $\beta$ is the width at midheight of the diffraction peaks (FWHM) determined by the Match refinement.

Thus, we can follow the epsilon micro-deformation according to the law [18]:

$$
\varepsilon=\frac{\beta}{4 \cos \theta}
$$

According to the figure illustrating the X-ray diffraction, the FWHM increases with the addition of Mn, which induces a remarkable decrease in the size of the nano-crystallites with the increase in the amount of dopant from $144.366 \mathrm{~nm}$ to $57.729 \mathrm{~nm}$ for the high intensity peak, corresponds to the Miller index (110) (Table2).

In fact, the diffusion of manganese ions into the ceramic leads to a reduction of the grain size which is mainly related to the appearance of oxygen vacancies. These results are grouped in Table 2.

\subsection{Surface morphology:}

Figure 3 displays the micrographs of the BCZT and BCZT-xMn ceramics using the SEM analysis. The images taken of the different samples clearly depict a non-homogeneous particle size distribution. The addition of a small amount of $\mathrm{Mn}$ in doped ceramics leads to a larger grain size than in BCZT ceramics. Such addition promotes the growth of the ceramic grains and therefore a substitution of the $\mathrm{B}$-site with $\mathrm{Mn}^{3+}$ and $\mathrm{Mn}^{4+}$ ions will occur, leading to the creation of oxygen vacancies and an improved mass and energy transfer.

\subsection{Dielectric Study}

To monitor the effect of Mn doping on the dielectric permittivity and dielectric losses of BCZT-xMn ceramics, measurements will be made for BCZT ceramics and both doped, and recorded in Figure 2 for a frequency range from $1 \mathrm{kHz}$ to $1 \mathrm{MHz}$. 
Figure 4 show that:

i) Maximum dielectric permittivity decreases with frequency.

ii) For the BCZT ceramics (fig.4a), the maximum temperature is close to room temperature and there is a slight dispersion at maximum.

iii) Both curves correspond to Mn doped ceramics (fig. $4 \mathrm{~b}$ and fig.4c), the peak widens as soon as the amount of Mn increases and the dielectric maximum decreases with a temperature shift associated with the maximum permittivity. It is also noted that there is a slight dispersion of the permittivity for $\mathrm{T} \leq \mathrm{T}_{\mathrm{m}}$ and the dielectric losses decrease with temperature for all samples. Indeed, $\mathrm{Ti}^{4+}$ ions are less chemically stable and are reduced to $\mathrm{Ti}^{3+}$ ions according to the equation (5):

$$
\mathrm{Ti}^{4+}+\frac{1}{2} \mathrm{O}_{\mathrm{O}}^{\mathrm{x}} \rightarrow \mathrm{Ti}^{3+}+\frac{1}{2} \mathrm{~V}_{\mathrm{o}}^{-}
$$

When the $\mathrm{Mn}^{4+}$ ions diffuse into the BCZT ceramic, they are substituted with the $\mathrm{Ti}^{3+}$ ions according to the reaction (6):

$$
\mathrm{Mn}^{4+}+\mathrm{Ti}^{3+} \rightarrow \mathrm{Mn}^{3+}+\mathrm{Ti}^{4+}
$$

This is notably linked to Mn additions, which limit the concentration of vacant oxygen positions and causes the decrease of the permittivity [22].

The dielectric permittivity in the paraelectric zone for a normal ferroelectric is given by the following Curie Weiss formula (7):

$$
\varepsilon_{\mathrm{r}}^{\prime}(\mathrm{T})=\frac{\mathrm{C}}{\mathrm{T}-\mathrm{Tm}}
$$

Where, $\mathrm{C}$ and $\mathrm{T}_{0}$ are the curie constant and Curie temperature respectively. The deviation from the curie law is due to the assembly of short-range nanopolar domains [23].

Uchino and Nomura proposed another form for the previous law of Curie Weiss given by the equation (8)[23,24]:

$$
\frac{1}{\varepsilon_{\mathrm{r}}^{\prime}}-\frac{1}{\varepsilon_{\mathrm{rmax}}^{\prime}}=\frac{(\mathrm{T}-\mathrm{Tm})^{\gamma}}{\mathrm{C}}
$$


With $\varepsilon_{\text {rmax }}^{\prime}$ is the maximum permittivity of ceramics, $\mathrm{C}$ is a multiplicative constant. $\gamma$ is a constant corresponding to the degree of diffuseness $[22,25,26]$ and it gives information on the phase transition in perovskite determined by the linear fit of the experimental data.

A plot of $\ln \left(\frac{1}{\varepsilon_{\mathrm{r}}^{\prime}}-\frac{1}{\varepsilon_{\mathrm{rmax}}^{\prime}}\right)=f\left(\ln T-T_{m}\right)$ drawn for $\mathrm{T}>\mathrm{T}_{\mathrm{c}}$ for a frequency of $1 \mathrm{kHz}$ allows us to obtain the value of $\gamma$ (Table 3 ).

The relaxation behavior is described by the quantity $\Delta \mathrm{T}_{\text {relax }}$ defined by:

$$
\Delta \mathrm{T}_{\text {relax }}=\mathrm{T}_{\mathrm{m}}(100 \mathrm{kHz})-\mathrm{T}_{\mathrm{m}}(1 \mathrm{kHz})
$$

This relaxation parameter increases from 1 to 2 with the growth of the quantity of Mn added (Table 3).

Figure 5 illustrates the variations of permittivity as a function of temperature for $\mathrm{f}=1 \mathrm{kHz}$, it allows us to go back to the values of maximum temperature $T_{m}$ relative to the maximum of dielectric permittivity, critical temperature $T_{0}$ and temperature $T_{d}$ from which the dielectric constant starts to deviate from Curie's law. For this purpose the degree of deviation from the Curie -Weiss law can be described by means of parameters $\Delta \mathrm{T}_{\mathrm{m}}$ defined as follows:

$$
\Delta \mathrm{T}_{\mathrm{m}}=\mathrm{T}_{\mathrm{d}}-\mathrm{T}_{\mathrm{m}}
$$

The values of this parameter increase if Mn concentration increases which suggests that $\mathrm{Mn}$ doping induces a diffusion of the ceramic phase transition BCZT. Where the diffuseness character of the phase transition is described by the following empiric parameter:

$$
\Delta \mathrm{T}_{\text {diff }}=T_{0.9 \varepsilon_{\text {rmax }}}(1 \mathrm{kHz})-T_{\varepsilon_{\text {rmax }}}(1 \mathrm{kHz})
$$

The value of this parameter indicates the effect of doping ceramics BCZT-xMn. The main values extracted from the study on the ceramic dielectric of BCZT doped Mn are summarized in Table 3.

Figure 7 describes the variations of dielectric permittivity and dielectric losses as a function of frequency for $\mathrm{T}=\mathrm{T}_{\mathrm{m}}$ for a range from $1 \mathrm{kHz}$ to $1000 \mathrm{KHz}$. In this range, the dielectric constant is reduced as the frequency increases and decreases with Mn content due to the 
reduction in particle size with $\mathrm{MnO}_{2}$ doping. The dielectric losses vary slightly with frequency and a minimum value of around 0.01 can be recorded.

Figure 8 shows the conductivity measured at the critical temperature $\mathrm{T}_{\mathrm{m}}$ as a function of the frequency of the BCZT ceramic. It is defined according to the following relationship:

$$
\sigma_{a c}=\omega \varepsilon_{0} \varepsilon_{1} \tan \varepsilon_{1}
$$

Where $\omega$ is the angular frequency, both $\varepsilon_{0}$ and $\varepsilon_{1}$ are the dielectric constants of vacuum and the relative dielectric constant and $\tan \varepsilon_{1}$ is the dielectric loss. However, it can be seen that conductivity is highly frequency-dependent and follows a linear variation. It increases with frequency, which implies a decrease in resistance according to the law:

$$
\mathrm{R}=\frac{l}{\sigma \mathrm{S}}
$$

The conductivity also reduces with Mn doping as a result of the presence of defects or impurities in the ceramic.

\section{Conclusion}

BCZT and BCZT-xMn doped ceramics are successfully prepared by the solid-solid method. The DRX spectra highlight the presence of the pure phase of the material, indicating that the $\mathrm{Mn}^{4+}$ ions are well integrated in the perovskite while maintaining the solid solution. The addition of Mn reduces the permittivity of doped ceramics and reduces dielectric losses. In fact, the addition of manganese oxide reduces the concentration of vacant oxygen by occupying the perovskite site $\mathrm{B}$ while substituting with $\mathrm{Ti}^{4+}$ ions and also reduces the size of the grains.

In fact, DRX shows that the Mn doping decreases the granular size, in accordance with the values of the crystallite size which evolves from $144.36 \mathrm{~nm}$ for the parent compound up to $57.729 \mathrm{~nm}$ for an addition of $1 \%$ of $\mathrm{Mn}$ for the main peak (110). The low deformation of the 
perovskite is given by constant epsilon called micro deformation. The calculation of the mesh parameters indicates an orthorhombic structure of the ceramics.

SEM characterization allows us to trace the microstructure of ceramic compounds. The study of the dielectric part as a function of temperature for a frequency range from $1 \mathrm{kHz}$ to $1 \mathrm{MHz}$ indicates that the maximum relative permittivity (at temperature $\mathrm{T}_{\mathrm{m}}$ for $1 \mathrm{kHz}$ ) decreases by adding $\mathrm{Mn}$ of 3570.91 for $\mathrm{x}=0 \%, 1570.32$ for $\mathrm{x}=0.25 \%$ to 850.29 for $\mathrm{x}=1 \%$. The curve $\ln \left(1 / \varepsilon-1 / \varepsilon_{\mathrm{m}}\right)=\mathrm{f}\left(\ln \left(\mathrm{T}-\mathrm{T}_{\mathrm{m}}\right)\right)$ allows us to know the nature of the phase transition by following the values of the diffusion coefficient which varies between 1 and 2 . As well as the degree of deviation and the character of diffusion are respectively given by $\Delta \mathrm{T}_{\text {diff }}$ and $\Delta \mathrm{T}_{\mathrm{d}}$ at the frequency $1 \mathrm{kHz}$. The decrease in permittivity and dielectric losses as a function of frequency at maximum temperature can also be marked for each composition.

A study of the conductivity shows that it varies linearly as a function of the frequency at temperature $\mathrm{Tm}$ for each proportion of $\mathrm{Mn}$. 


\section{References:}

1. D. S. Keeble, F. Benabdallah, P. A. Thomas, M. Maglione, and J. Kreisel, Revised structural phase diagram of (Ba0.7Ca0.3TiO3)-(BaZr0.2Ti0.8O3), Appl. Phys. Lett.102, 092903 (2013).

2. A. Hamza, F. Benabdallah, I. Kallel, L. Seveyrat, L. Lebrun, and H. Khemakhem, Effect of rare-earth substitution on the electrical properties and Raman spectroscopy of BCTZ ceramics, Journal of Alloys and Compounds 735, 2523 (2018).

3. M. Siddiqui, J. J. Mohamed, and Z. A. Ahmad, Structural, piezoelectric, and dielectric properties of PZT-based ceramics without excess lead oxide, J Aust Ceram Soc 56, 371 (2020).

4. C. Xu, Z. Yao, K. Lu, H. Hao, Z. Yu, M. Cao, and H. Liu, Enhanced piezoelectric properties and thermal stability in tetragonalstructured $(\mathrm{Ba}, \mathrm{Ca})(\mathrm{Zr}, \mathrm{Ti}) \mathrm{O}$ piezoelectrics substituted with trace amount of Mn, Ceramics International 42, 16109 (2016).

5. P. Parjansri, K. Pengpat, G. Rujijanagul, T. Tunkasiri, U. Intatha, and S. Eitssayeam, Effects of Mn and Sr Doping on the Electrical Properties of Lead-Free 0.92BCZT-0.08BZT, Ceramics Ferroelectrics 458, 91 (2014).

6. D. Maurya, M. Peddigari, M.-G. Kang, L. D. Geng, N. Sharpes, V. Annapureddy, H. Palneedi, R. Sriramdas, Y. Yan, H.-C. Song, Y. U. Wang, J. Ryu, and S. Priya, Lead-free piezoelectric materials and composites for high power density energy harvesting, Journal of Materials Research 33, 2235 (2018).

7. W. Liu and X. Ren, Large Piezoelectric Effect in Pb-Free Ceramics, Phys. Rev. Lett. 103, 257602 (2009).

8. D. Damjanovic, A. Biancoli, L. Batooli, A. Vahabzadeh, and J. Trodahl, Elastic, dielectric, and piezoelectric anomalies and Raman spectroscopy of 0.5Ba(Ti0.8Zr0.2)O3-

0.5(Ba0.7Ca0.3)TiO3, Appl. Phys. Lett. 100, 192907 (2012). 
9 A. T. Dang, T. T. Vo, V. C. Truong, and V. H. Le, Inuence of sintering temperature on structure, microstructure and piezoelectric properties of doped BZT\{BCT ceramics, Int. J. Mod. Phys. B 31, 1650258 (2016).

10. A. D. Loreto, A. Frattini, R. Machado, O. de Sanctis, and M. G. Stachiotti, Preparation and Characterization of Mn-Doped (Ba0.85 ca0.15)(Zr0.1 Ti0.9)O3Ceramics, Ferroelectrics 463, 105 (2014).

11. N. Othmani, A. Amouri, F. Benabdallah, Z. Sassi, L. Seveyrat, L. Lebrun, V. Perrin, and H. Khemakhem, Effect of bismuth doping on structural and electrical properties of0.9(BaZr0.2Ti0.8O3)-0.1(Ba0.7Ca0.3TiO3) ceramic, Ceramics International 46, 22592 (2020).

12. J. Ravez, C. Broustera, and A. Simon, Lead-free ferroelectric relaxor ceramics in the BaTiO-BaZrO3-CaTiO3system, Journal of Materials Chemistry 9, 1609 (1999).

13. H. Kaddoussi, A. Lahmar, Y. Gagou, B. Manoun, J. N. Chotard, J.-L. Dellis, Z. Kutnjak, H. Khemakhem, B. Elouadi, and M. El Marssi, Sequence of structural transitions and electrocaloric properties in (Ba1-x Ca x(Zr0.1Ti0.9)O3, ceramics Journal of Alloys and Compounds 713, 164 (2017).

14. P. Jaiban, P. Wannasut, R. Yimnirun, and A. Watcharapasorn, Influences of acceptor dopants $(\mathrm{Cu}, \mathrm{Mg}, \mathrm{Fe})$ on electrical and optical properties of $\mathrm{Ba} 0.7 \mathrm{Ca} 0.3 \mathrm{TiO} 3$, ceramics, Materials Research Bulletin 118, 110501 (2019).

15. F. Feng and Y. Yan, Large electrostrictive effect in Mn-doped BCZT ferroelectric ceramics, Ceramics International 45, 21315 (2019).

16. P. Parjansri and S. Eitssayeam, Effects of MnO2doping on the electrical properties of BCZT ceramics prepared by seed-induced method, Ferroelectrics 534, 63 (2018). 17. O. Kamoun, A. Boukhachem, M. Amlouk, and S. Ammar, Physical study of Eu doped MoO3 thin films, Journal of Alloys and Compounds 687, 595 (2016). 
18. B. Gharbi, A. Boukhachem, M. Amlouk, M. Oueslati, B. Dkhil, and A. Meftah, Physical investigations on LaMn1xNixO3perovskite sprayed thin films along with surface magnetic applications, Appl. Phys. A 126, 604 (2020).

19. A. Loukil, A. Boukhachem, M. Ben Amor, M. Ghamnia, and K. Raouadi, Effects of potassium incorporation on the structural, optical,vibrational and electrical properties of $\mathrm{NiO}$ sprayed thin films for p-type optical windows, Ceramics International 42, 8274 (2016). 20. G. Bousselmi, N. Khemiri, A. Benali, M. P. F. Graca, R. F. Santos, B. F. O. Costa, and M. Kanzari, Synthesis and study of structural, optical, and electrical properties of nontoxic and earth-abundant Na2ZnSnS4material, J Mater Sci: Mater Electron 31, 18858 (2020).

21. A. Boukhachem, M. Mokhtari, N. Benameur, A. Ziouche, M. Martínez, P. Petkova, M. Ghamnia, A. Cobo, M. Zergoug, and M. Amlouk, Structural Optical Magnetic Properties of Co doped $\alpha$-MoO3sprayed thin Films Sensors and Actuators A: Physical 253, 198 (2017). 22. W. Cai, C. Fu, J. Gao, and X. Deng, Effect of Mn doping on the dielectric properties of BaZr0.2Ti0.8O3ceramics, J Mater Sci: Mater Electron 21, 317 (2010).

23. I. Djemel, I. Kriaa, N. Abdelmoula, and H. Khemakhem, The effect of low Sn doping on the dielectric and electrocaloric properties of ferroelectric ceramics Ba0.95Sr0.05Ti0.95Zr0.05O3,Journal of Alloys and Compounds 720, 284 (2017).

24. K. Uchino and S. Nomura,Critical exponents of the dielectric constantsdiffused-phase-transition crystals, Ferroelectrics 44, 55 (1982).

25. F. Bahri and H. Khemakhem, Relaxor behavior and dielectric properties of Ba1xBi2x/3Zr0.15Ti0.85O3 solid solution, Journal of Alloys and Compounds 593, 202 (2014).

26. L. Khemakhem, I. Kriaa, M. Derbel, and N. Abdelmoula, X-ray and dielectric studies of ferroelectric phase in the $\mathrm{Ba} 1-\mathrm{x}(\mathrm{Yb} 0.5 \mathrm{Na} 0.5) \mathrm{x} \mathrm{TiO} 3$ system for low doping level, Int. J. Nanoelectronics and Materials 2, 137-145 (2009). 


\section{Figure captions:}

Fig.1: Schematic representation of the BT-BZ-CT ternary diagram

Fig.2: X-ray diffraction pattern of the Mn $(0 \%, 0.25 \%$ and $1 \%)$ doped BCZT

Fig.3: SEM micrographs of surface BCZT-xMn ceramics ( $a: x=0 \%, b: 0.25 \%$ and $\mathrm{c}: 1 \%$ ).

Fig.4: Temperature dependence of dielectric constant and loss for BCZT-xMn ceramics.

Fig.5: Temperature dependence of inverse dielectric constant for BCZT-xMn ceramics

Fig.6: $\ln \left(1 / \varepsilon-1 / \varepsilon_{\max }\right)$ as a function of $\operatorname{Ln}\left(\mathrm{T}-\mathrm{T}_{\mathrm{m}}\right)$ for the BCTZ-xMn $(\mathrm{x}=0 \%, 0.25 \%$ and $1 \%)$ ceramics at $10 \mathrm{kHz}$.

Fig.7: Dielectric constant and dielectric loss as functions of frequency for BCZT-xMn ceramics at $\mathrm{T}=\mathrm{T}_{\mathrm{m}}$

Fig.8: AC conductivity as function of frequency for Mn doped for BCZT-xMn $(\% \mathrm{x}=0,0.25$, 1) at $\mathrm{T}_{\mathrm{m}}$.

\section{Tables captions:}

Table1: Lattice parameters of BCZT- xMn $(\% \mathrm{x}=0,0.25,1)$

Table2: Grain size and micro-strain of BCZT-xMn ceramics

Table 3: Dielectric properties of BCZT-xMn ceramics. 
Table1:

\begin{tabular}{|c|c|c|c|c|}
\hline BCZT-xMn & $\mathbf{a}(\mathbf{A})$ & b (A) & $\mathbf{c}(\mathbf{A})$ & c/a \\
\hline $\mathbf{x = 0 \%}$ & 4.0512 & 4.0447 & 4.0507 & 0.9998 \\
\hline $\mathbf{x = 0 . 2 5 \%}$ & 4.0488 & 4.0474 & 4.0542 & 1.0013 \\
\hline $\mathbf{x = 1 \%}$ & 4.0783 & 4.0033 & 4.0777 & 0.9998 \\
\hline
\end{tabular}

Table 2:

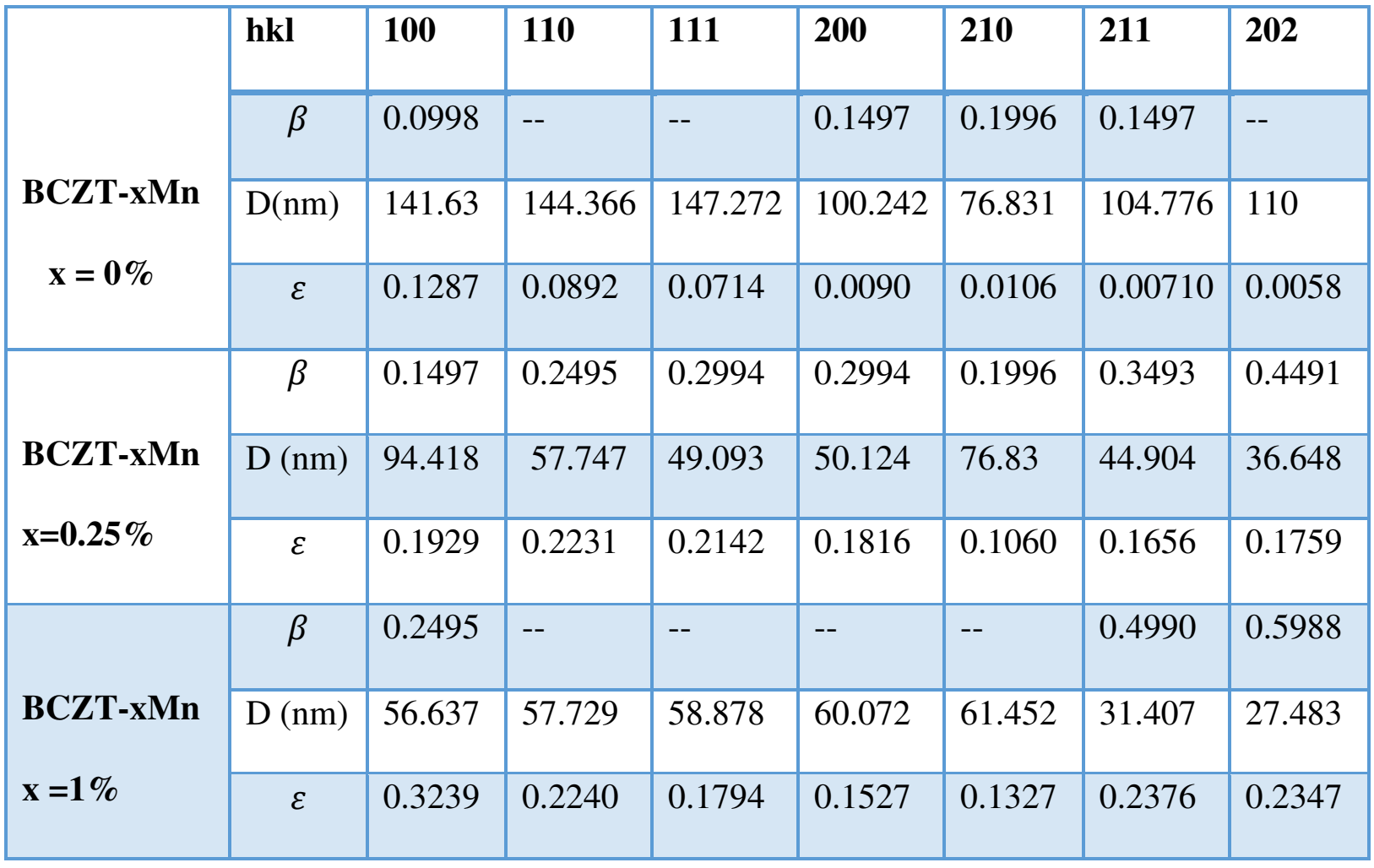

Table 3:

\begin{tabular}{|c|c|c|c|c|c|c|}
\hline \% $\mathbf{x}$ & $\mathbf{T}_{\mathbf{m}}(\mathbf{K})$ & $\boldsymbol{\varepsilon}_{\mathbf{m}} \mathbf{a t} \mathbf{1} \mathbf{~ k H z}$ & $\Delta \mathbf{T}_{\text {diff }}(\mathbf{K})$ & $\Delta \mathbf{T}_{\mathbf{m}}(\mathbf{K})$ & $\Delta \mathbf{T}_{\text {relax }}(\mathbf{K})$ & $\boldsymbol{\gamma}$ \\
\hline $\mathbf{0}$ & 302 & 3570.91 & 11.75 & 33.89 & 1.045 & 1.29 \\
\hline $\mathbf{0 . 2 5}$ & 304 & 1570.32 & 28.3 & 57.65 & 1.568 & 1.89 \\
\hline $\mathbf{1}$ & 317 & 850.29 & 51.58 & 59.8 & 2.091 & 1.92 \\
\hline
\end{tabular}




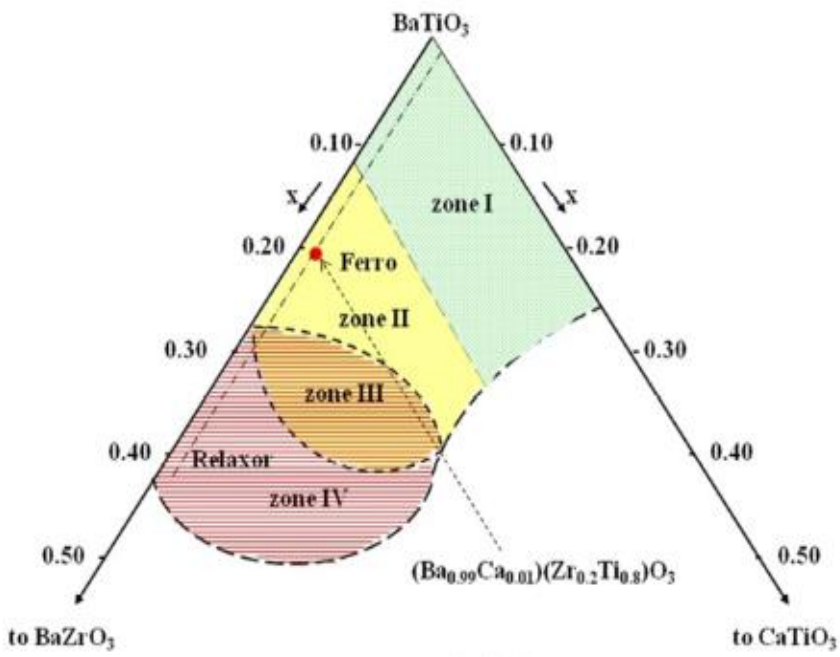

Fig.1 


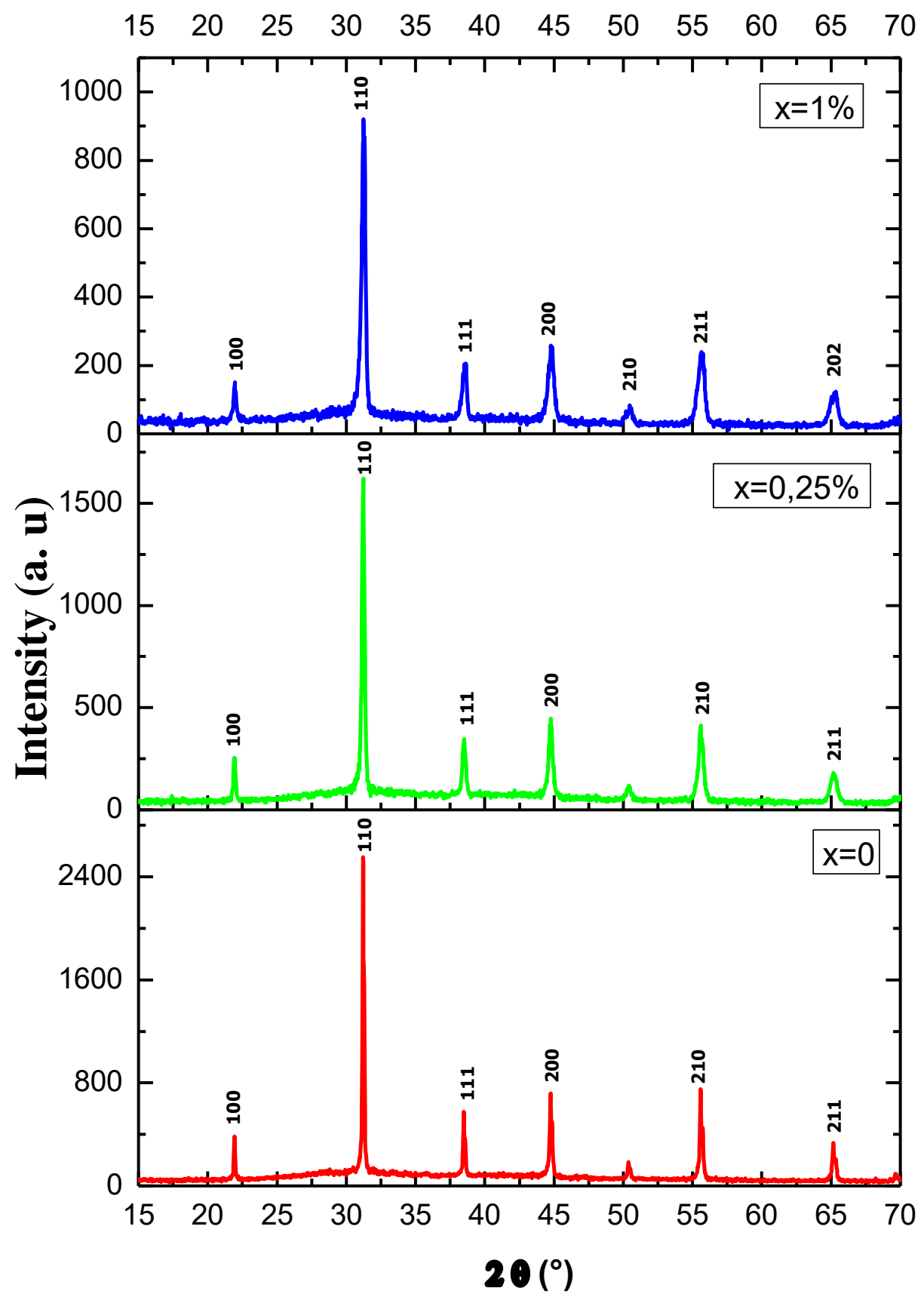

Fig.2 

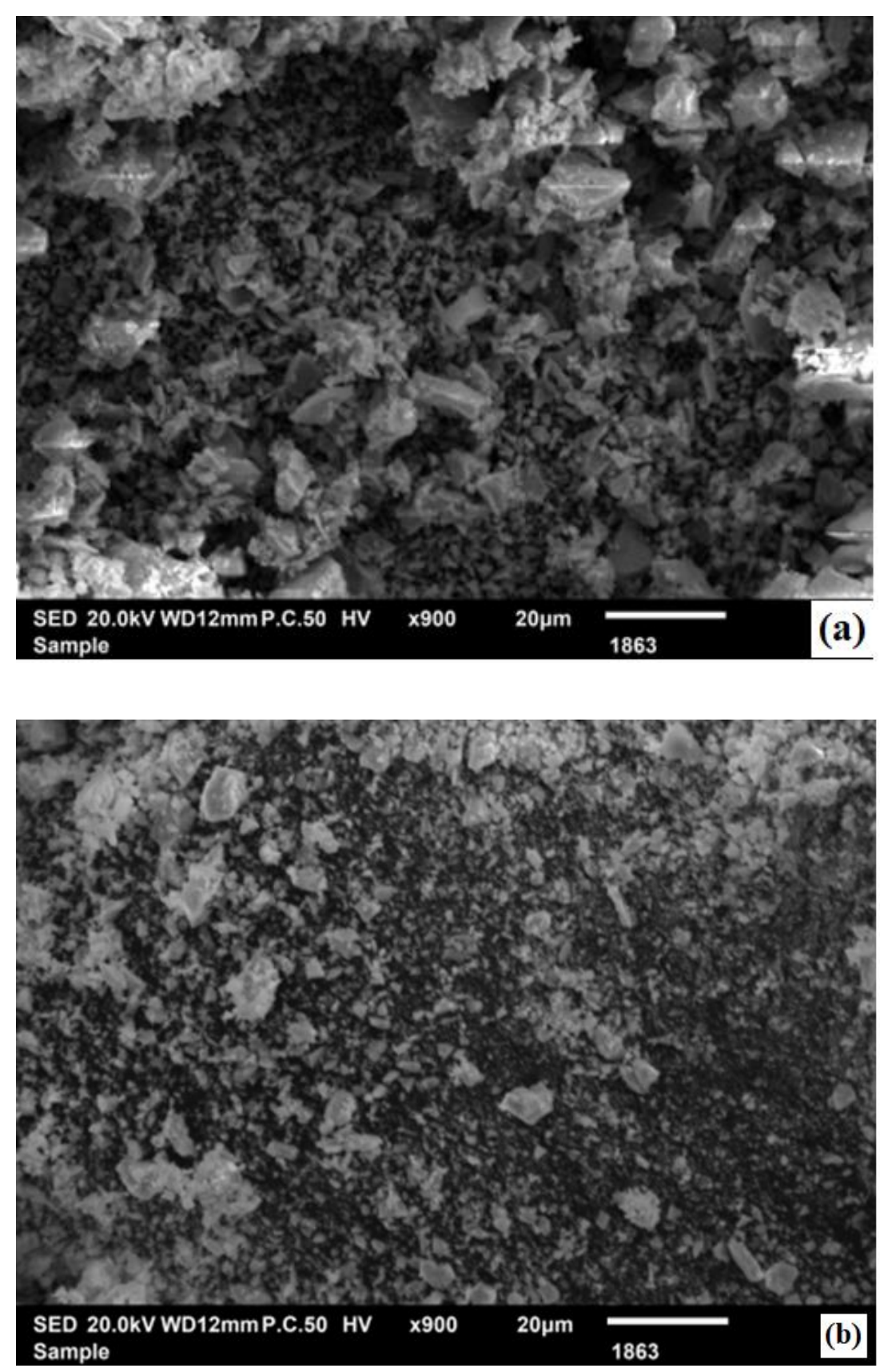


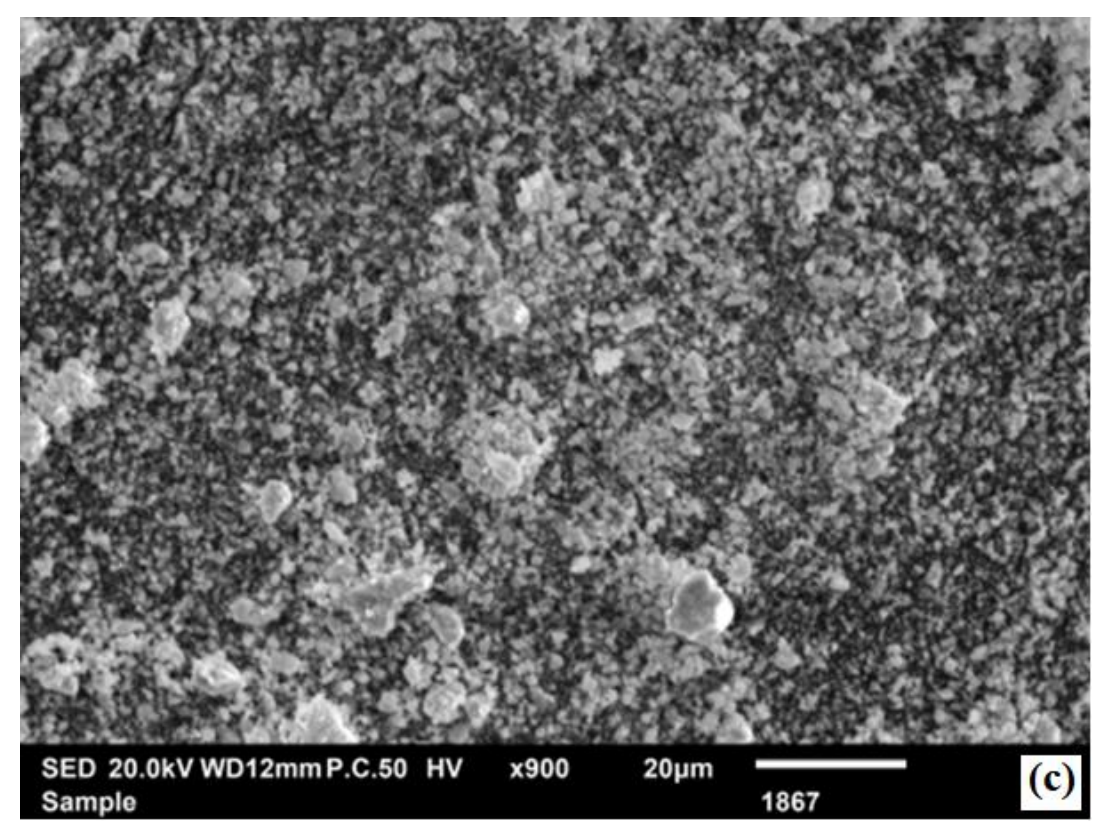

Fig.3 

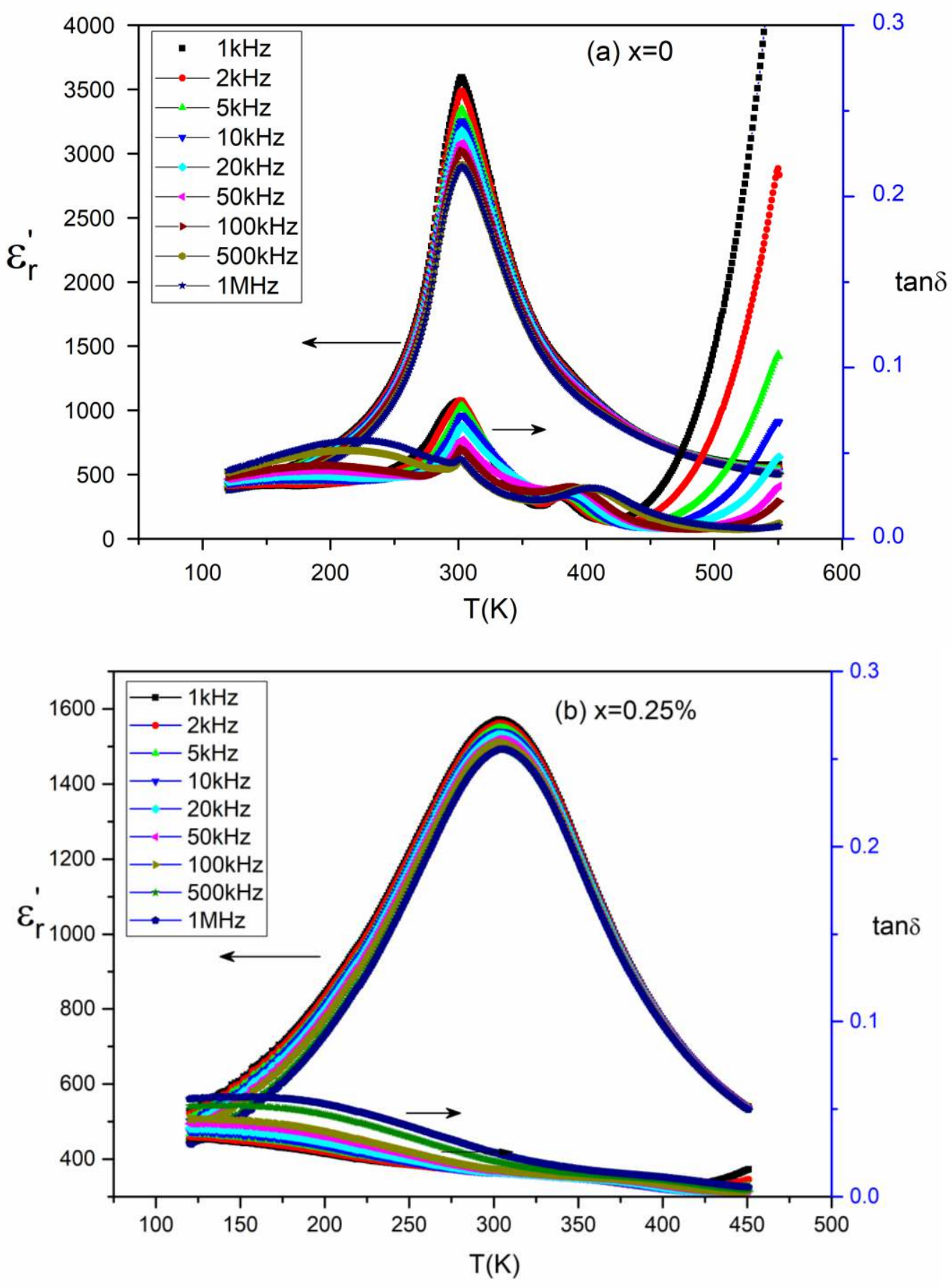


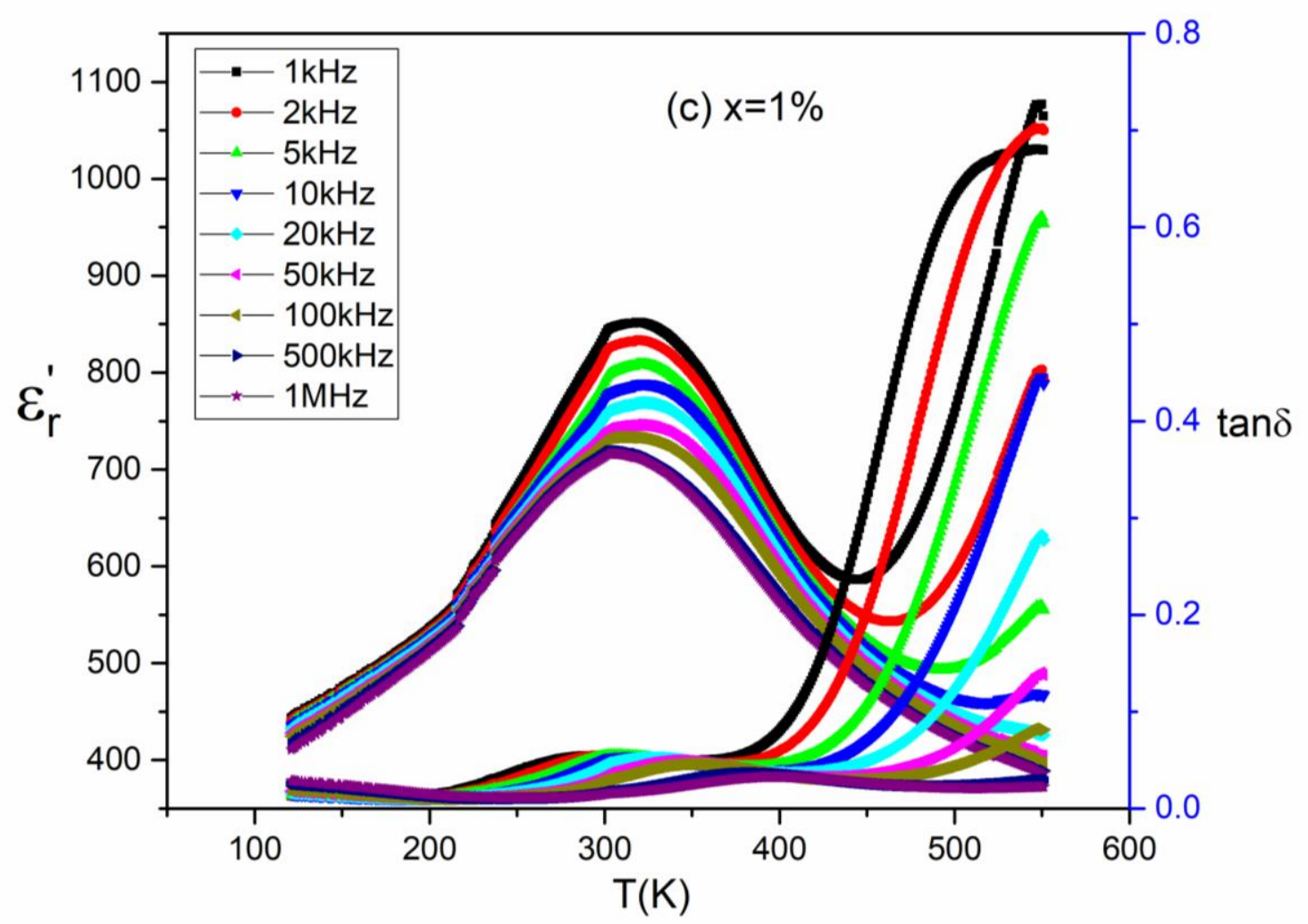

Fig.4 

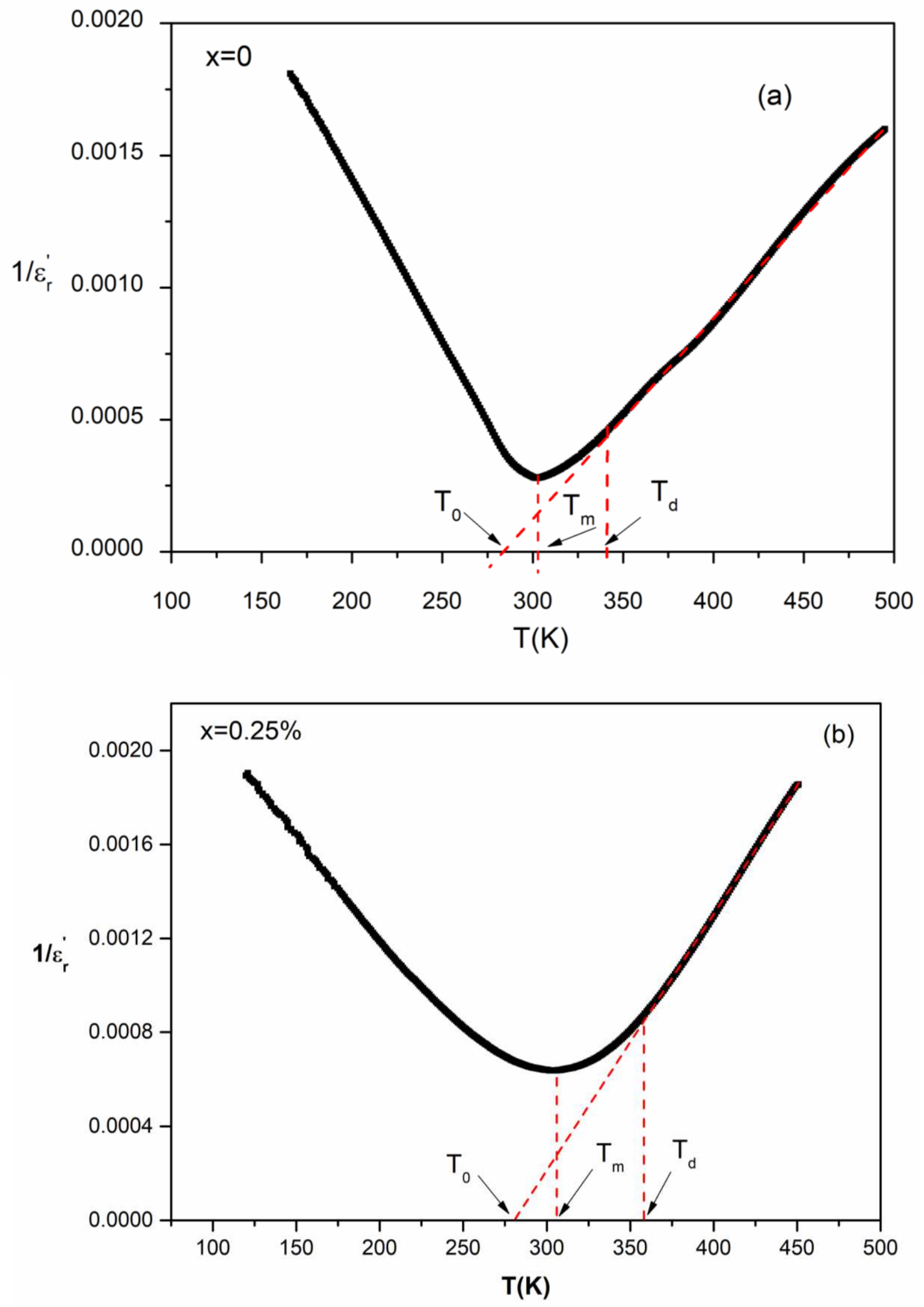


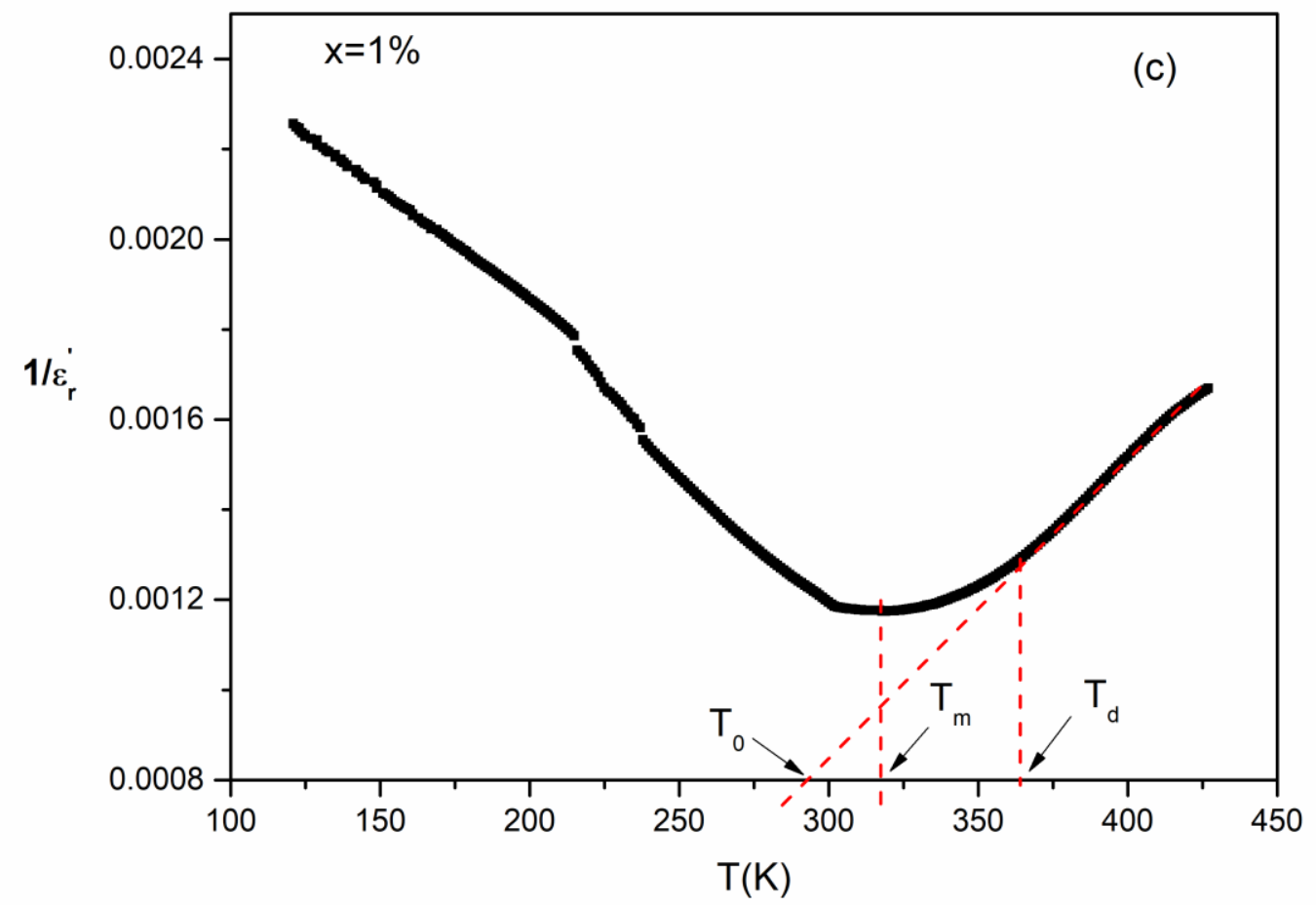

Fig.5 

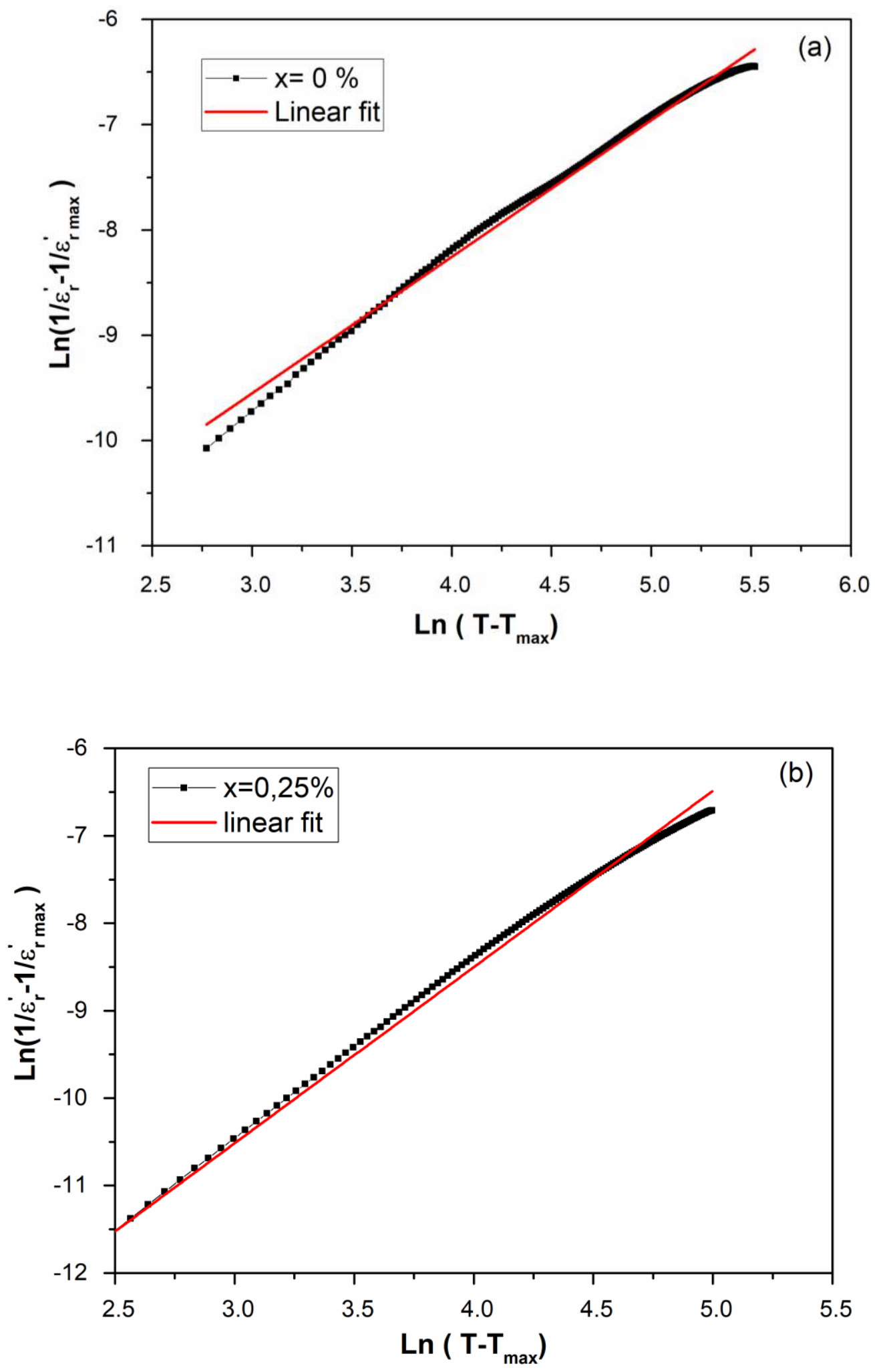


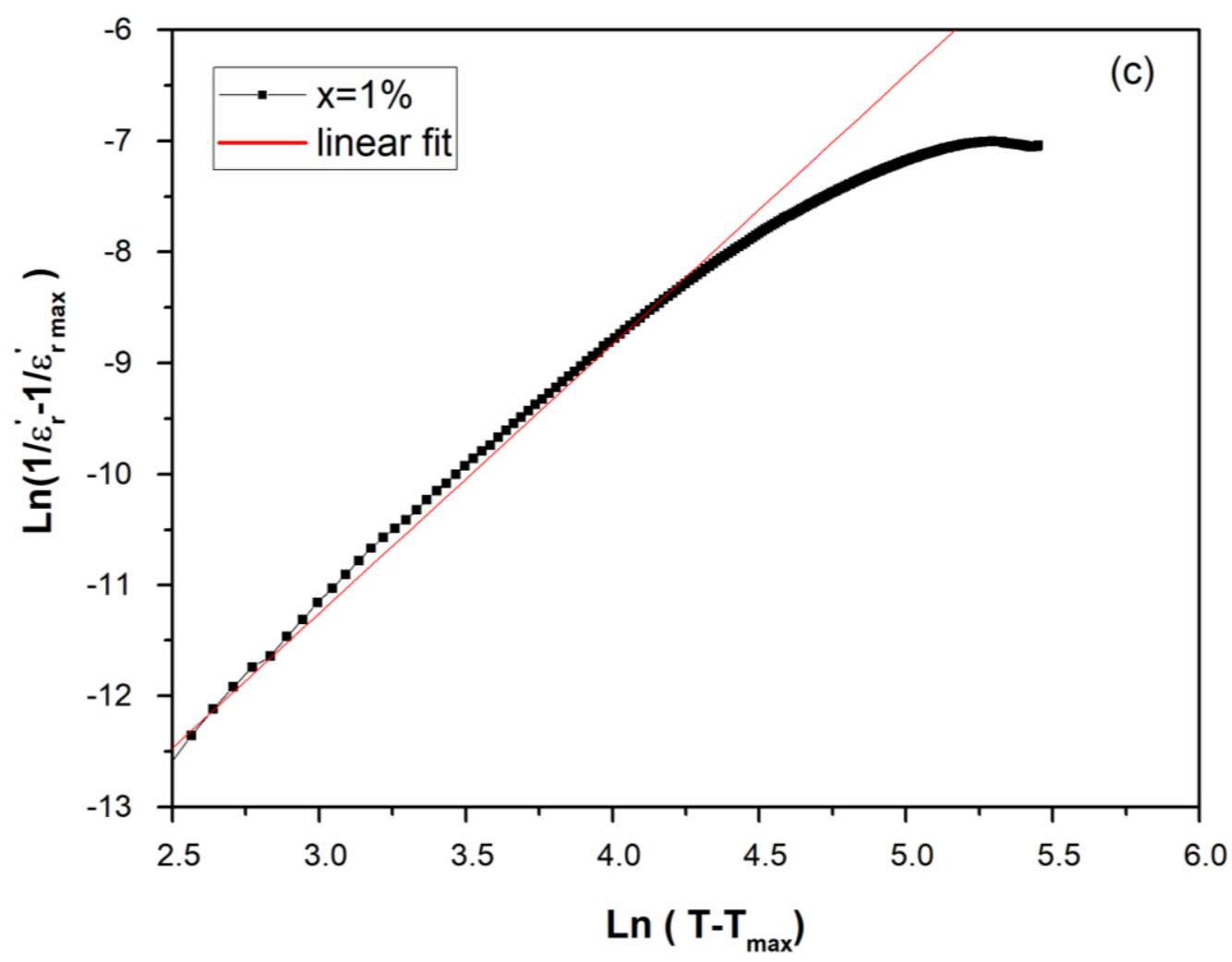

Fig.6 


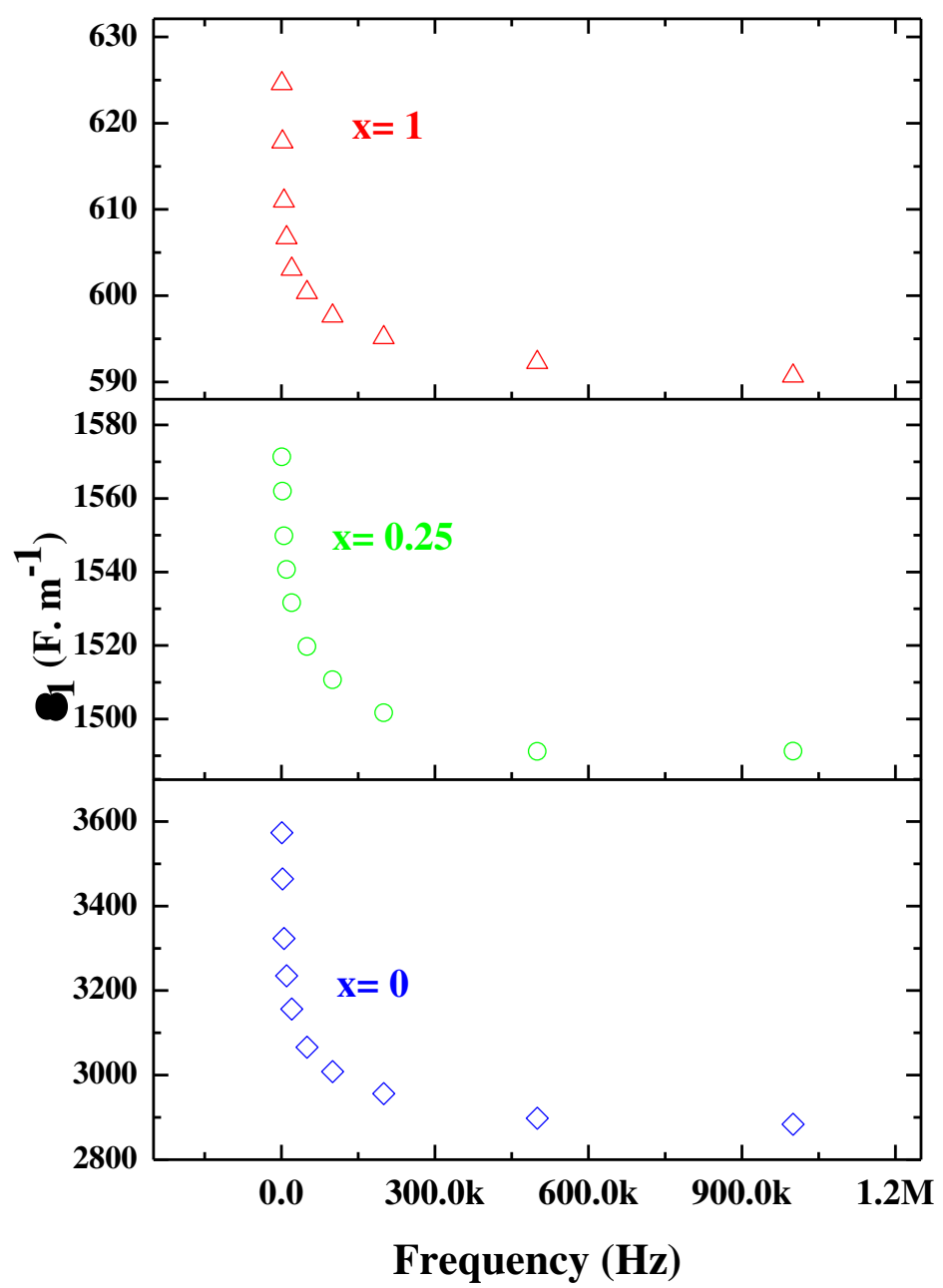




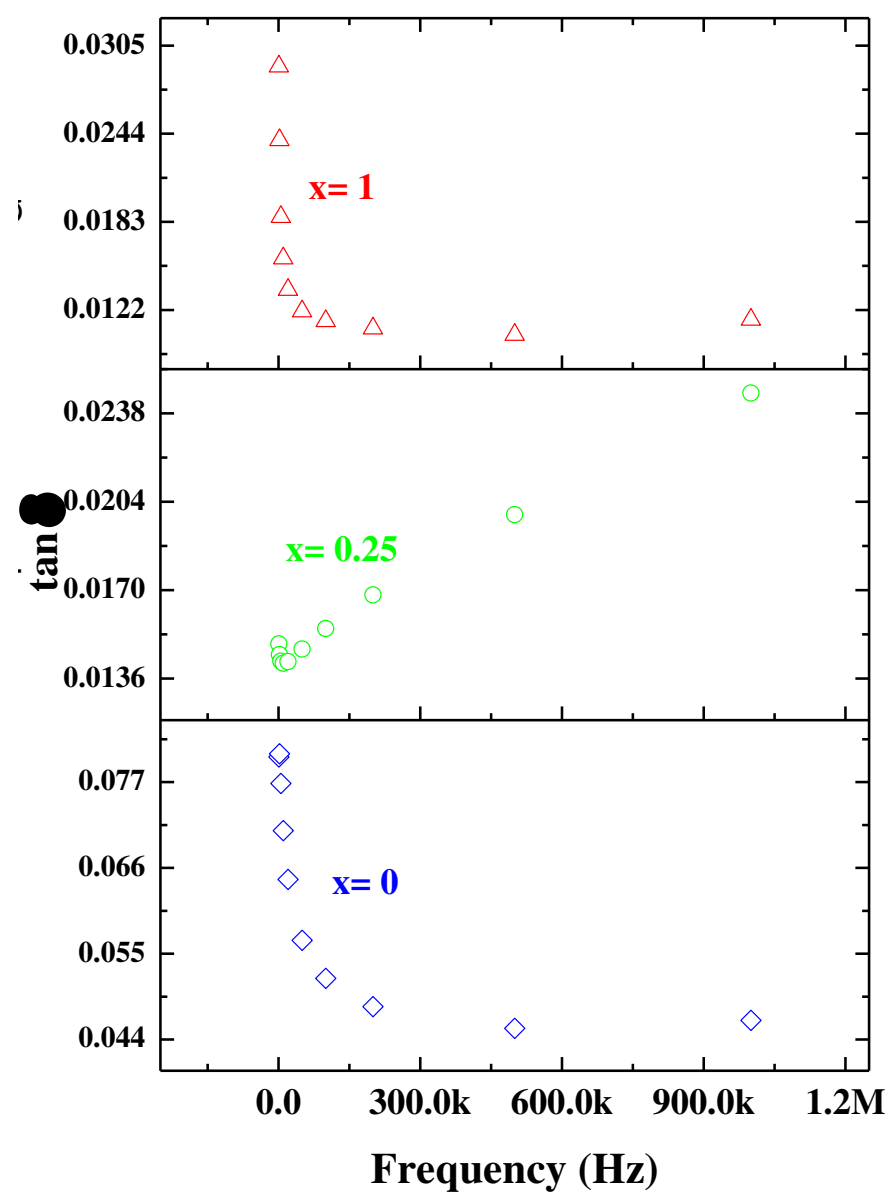

Fig.7 


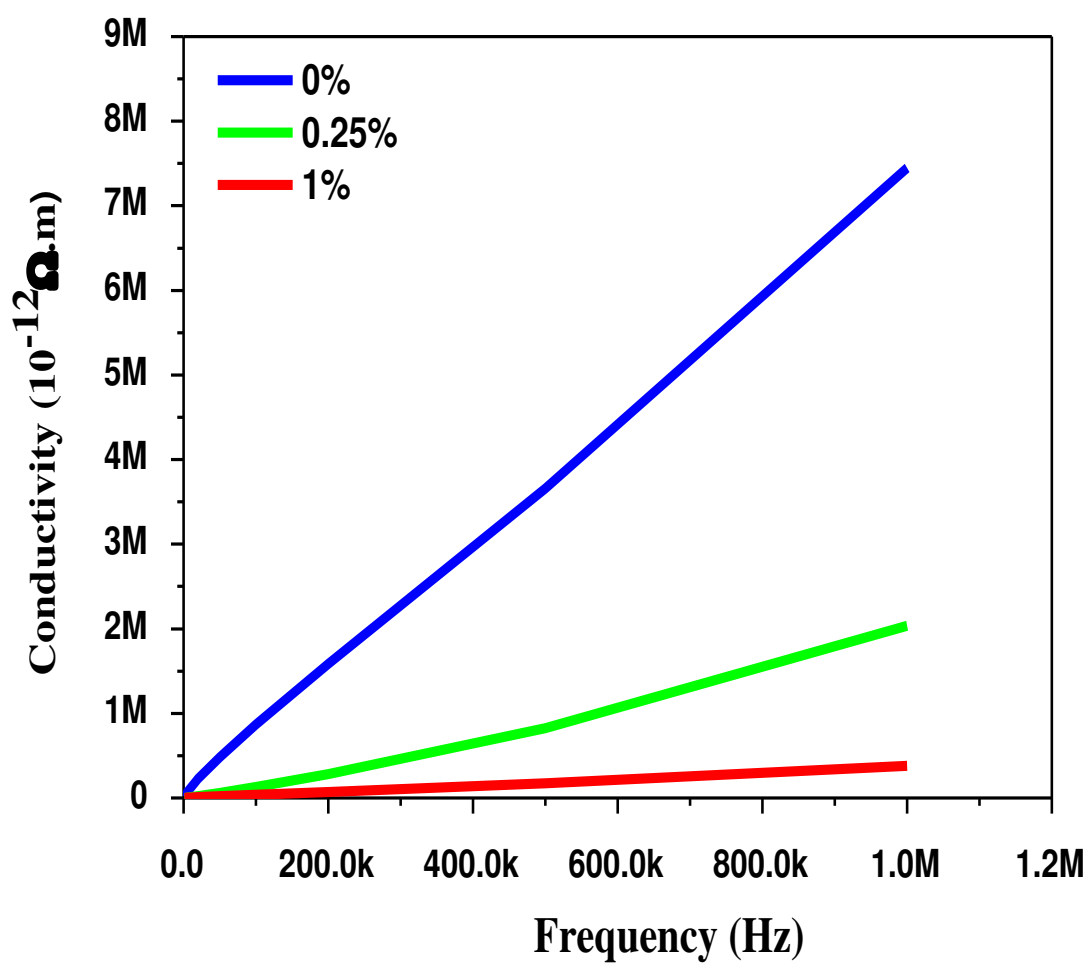

Fig.8 
Figures

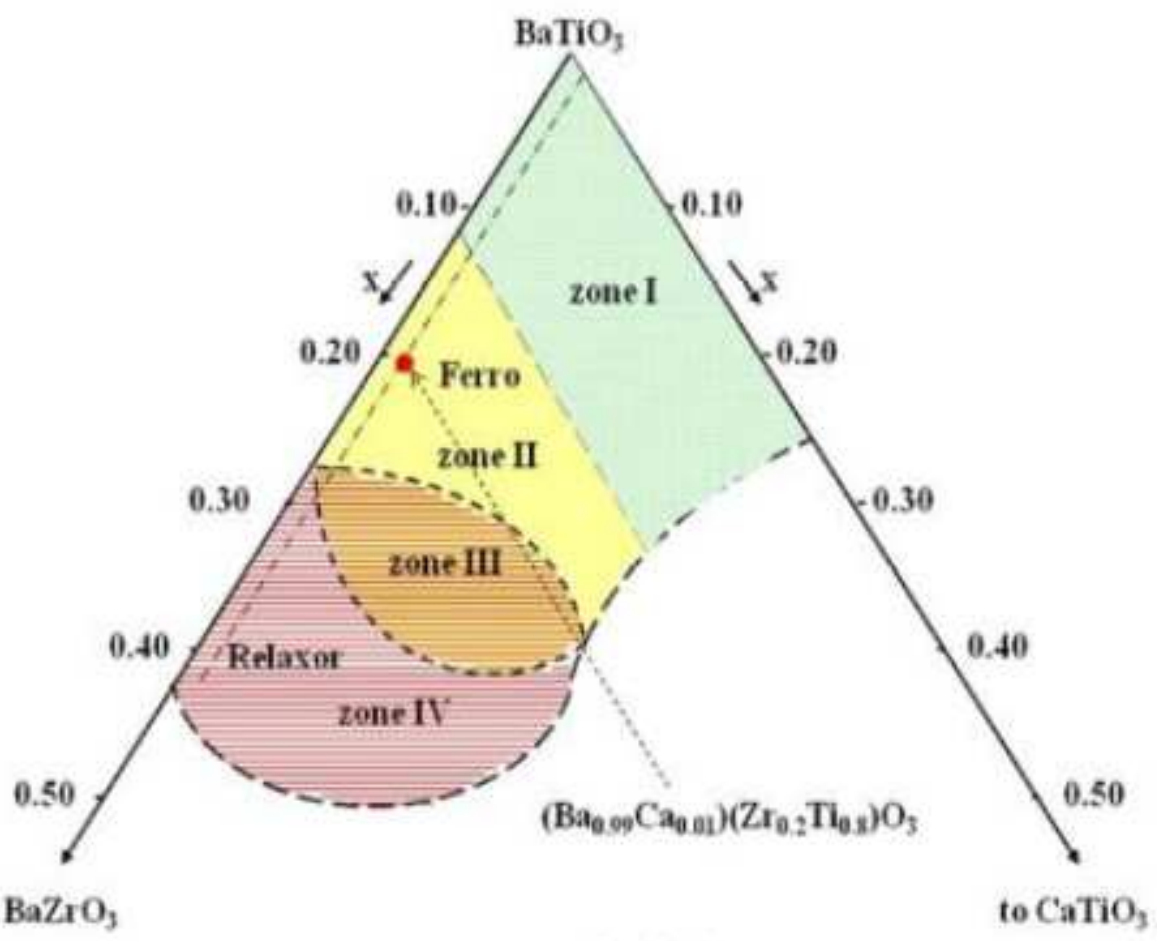

\section{Figure 1}

Schematic representation of the BT-BZ-CT ternary diagram 


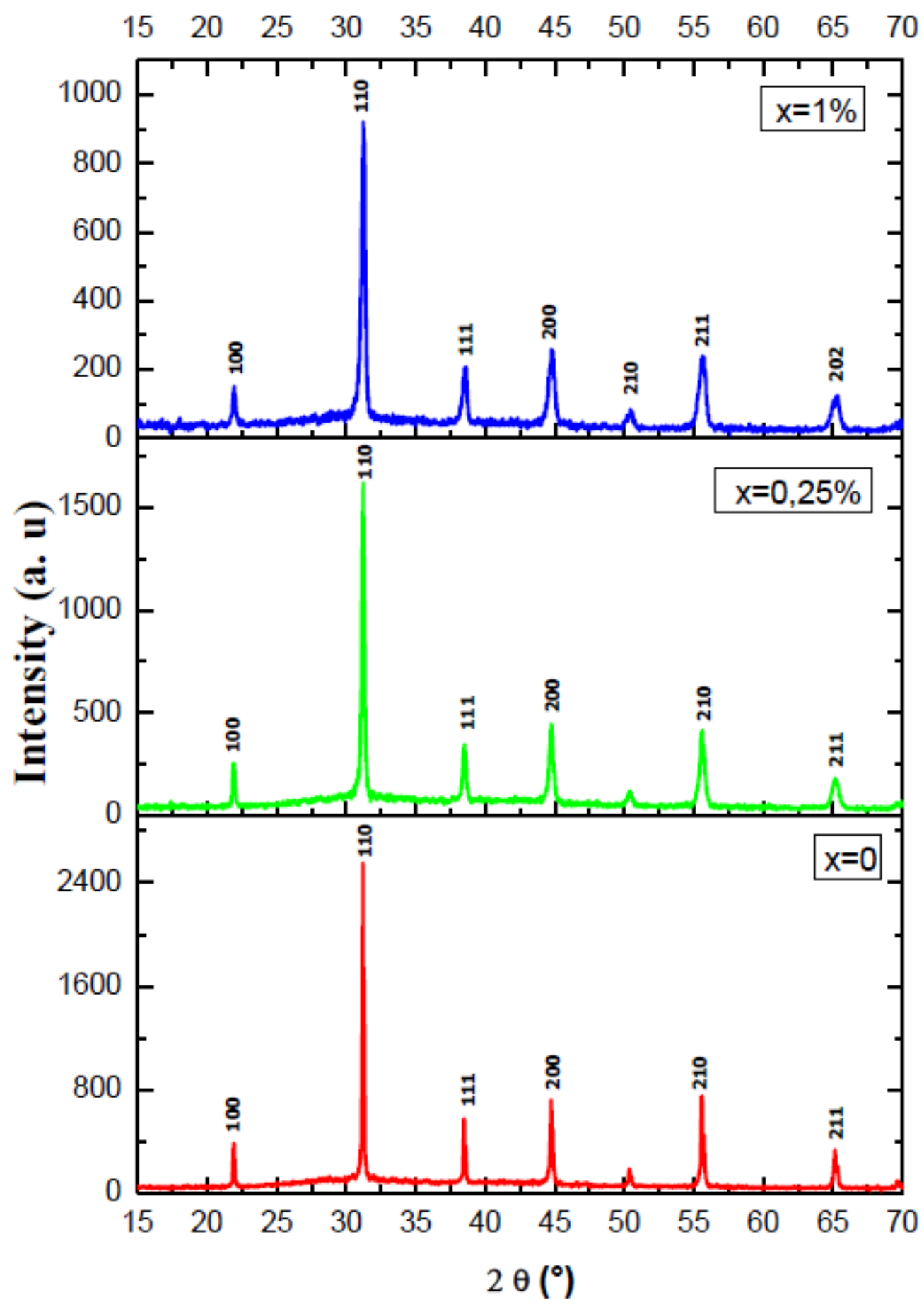

Figure 2

X-ray diffraction pattern of the $\mathrm{Mn}(0 \%, 0.25 \%$ and $1 \%)$ doped BCZT 

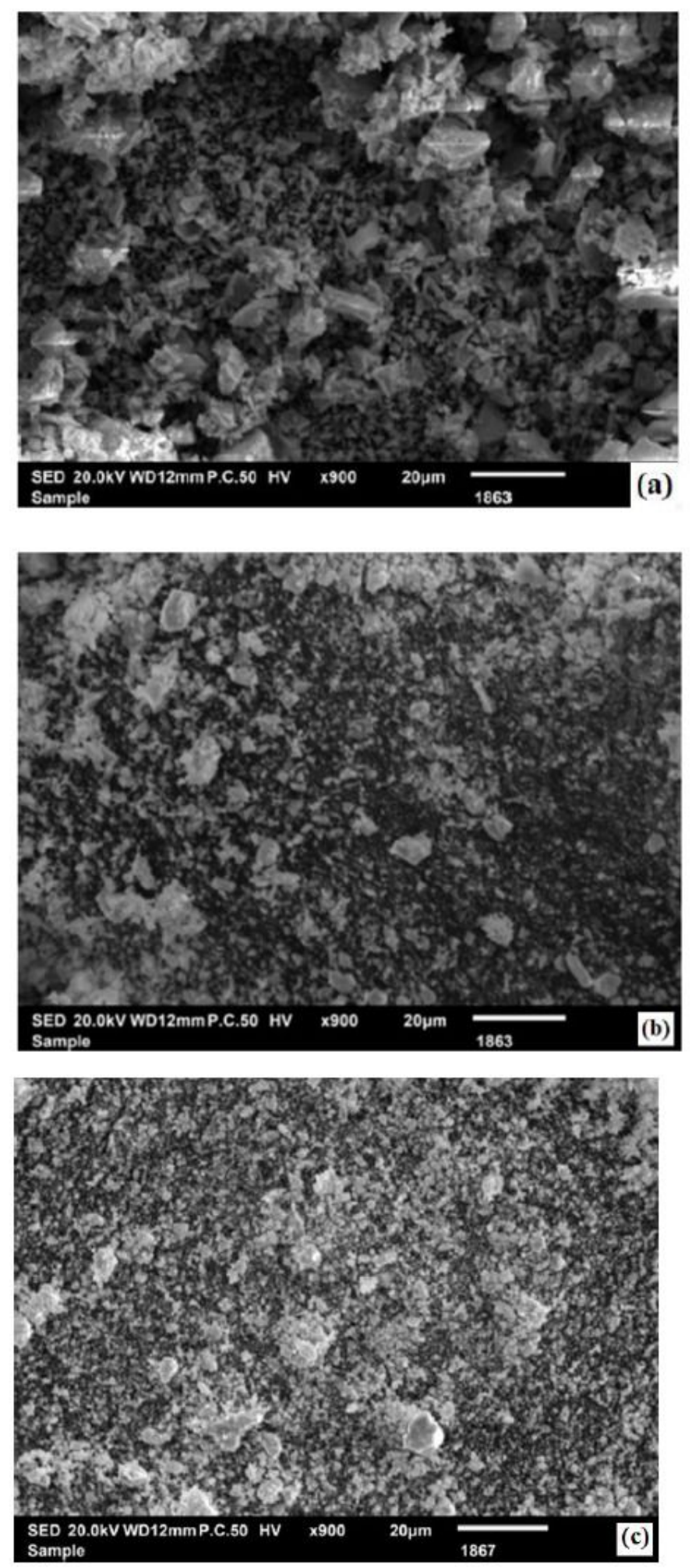

\section{Figure 3}

SEM micrographs of surface BCZT-xMn ceramics (a: $x=0 \%, b: 0.25 \%$ and $c: 1 \%)$. 

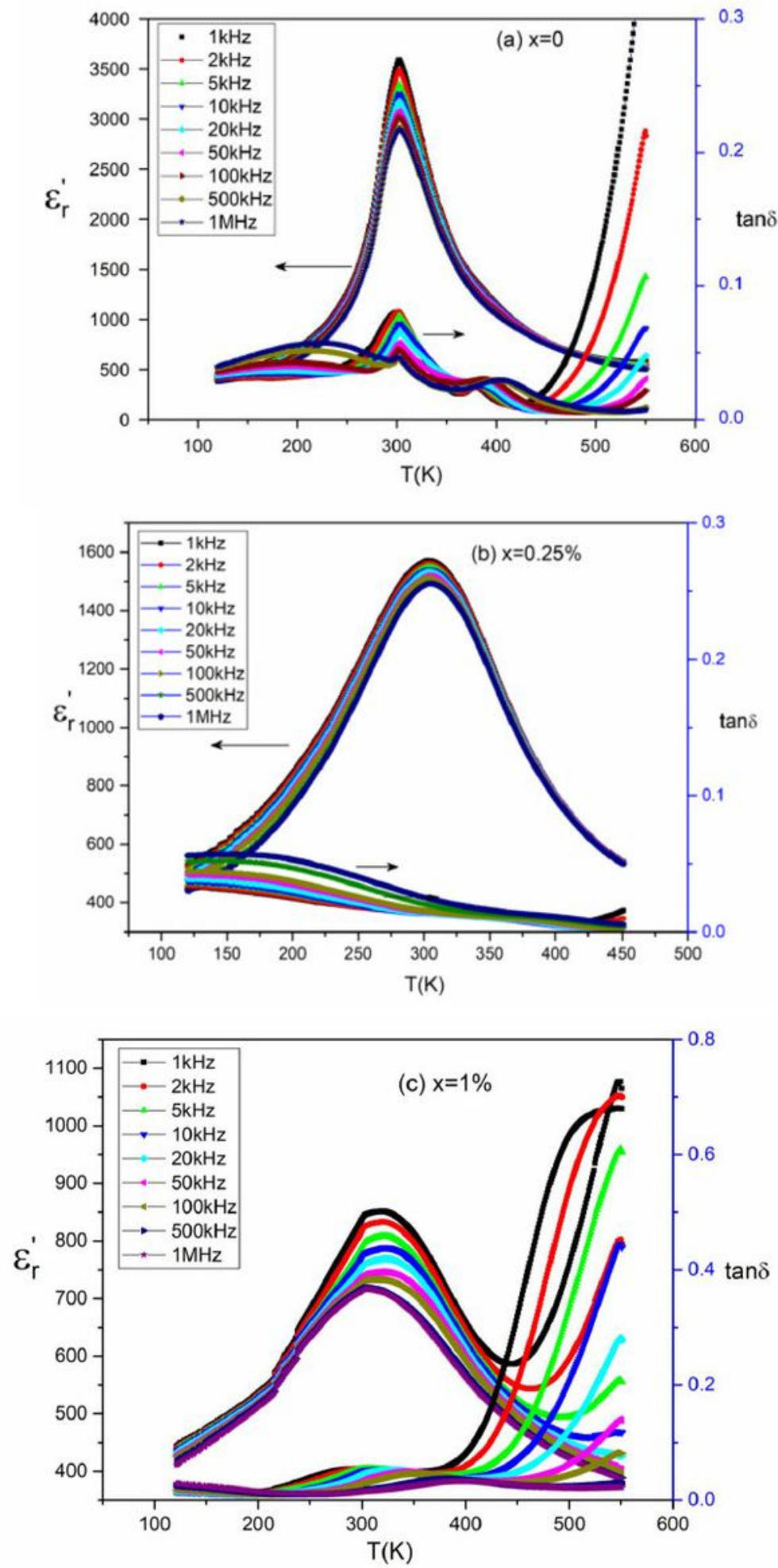

Figure 4

Temperature dependence of dielectric constant and loss for BCZT-xMn ceramics. 

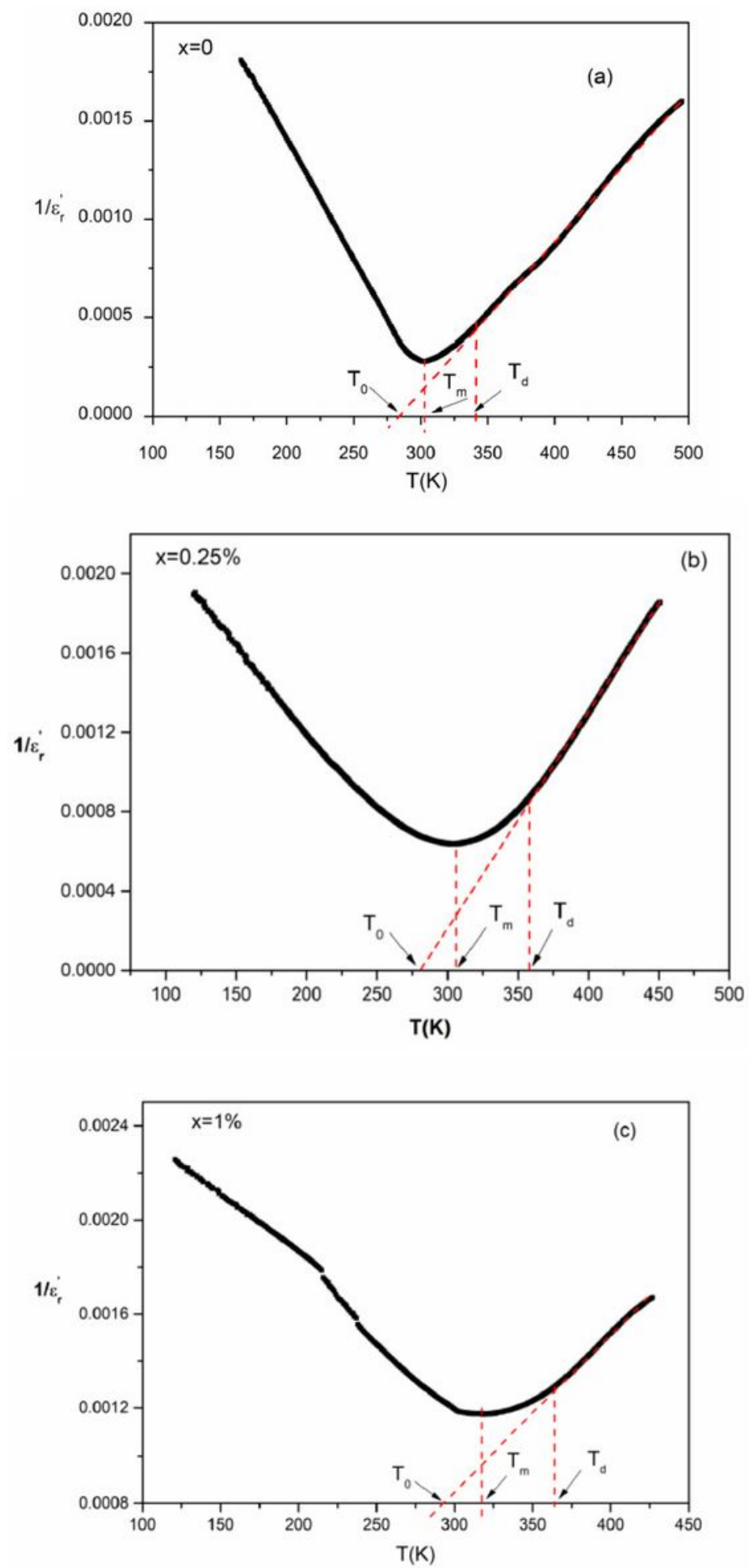

Figure 5

Temperature dependence of inverse dielectric constant for BCZT-xMn ceramics 

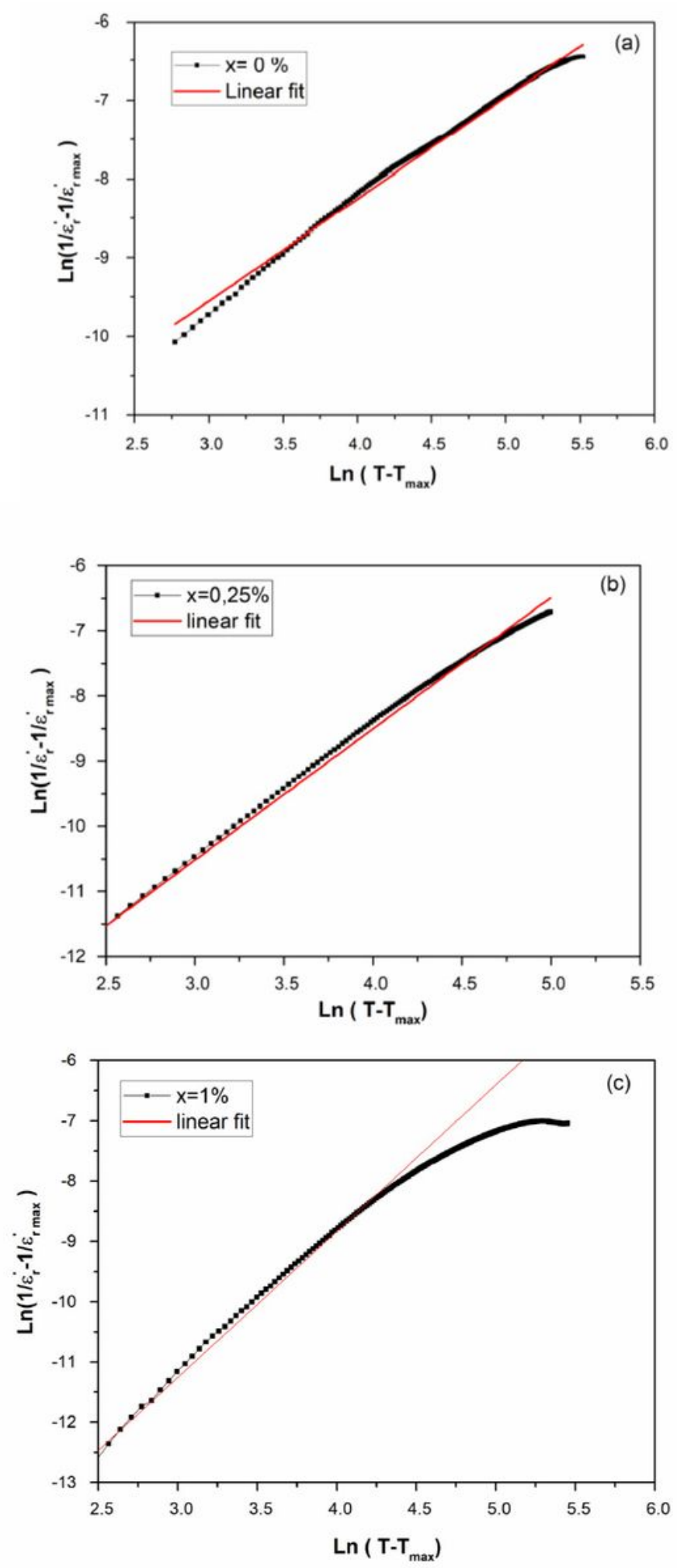

\section{Figure 6}

$\ln (1 / \mathbb{\nabla}-1 /$ \max $)$ as a function of $\operatorname{Ln}(T-T m)$ for the BCTZ-xMn $(x=0 \%, 0.25 \%$ and $1 \%)$ ceramics at 10 $\mathrm{kHz}$. 

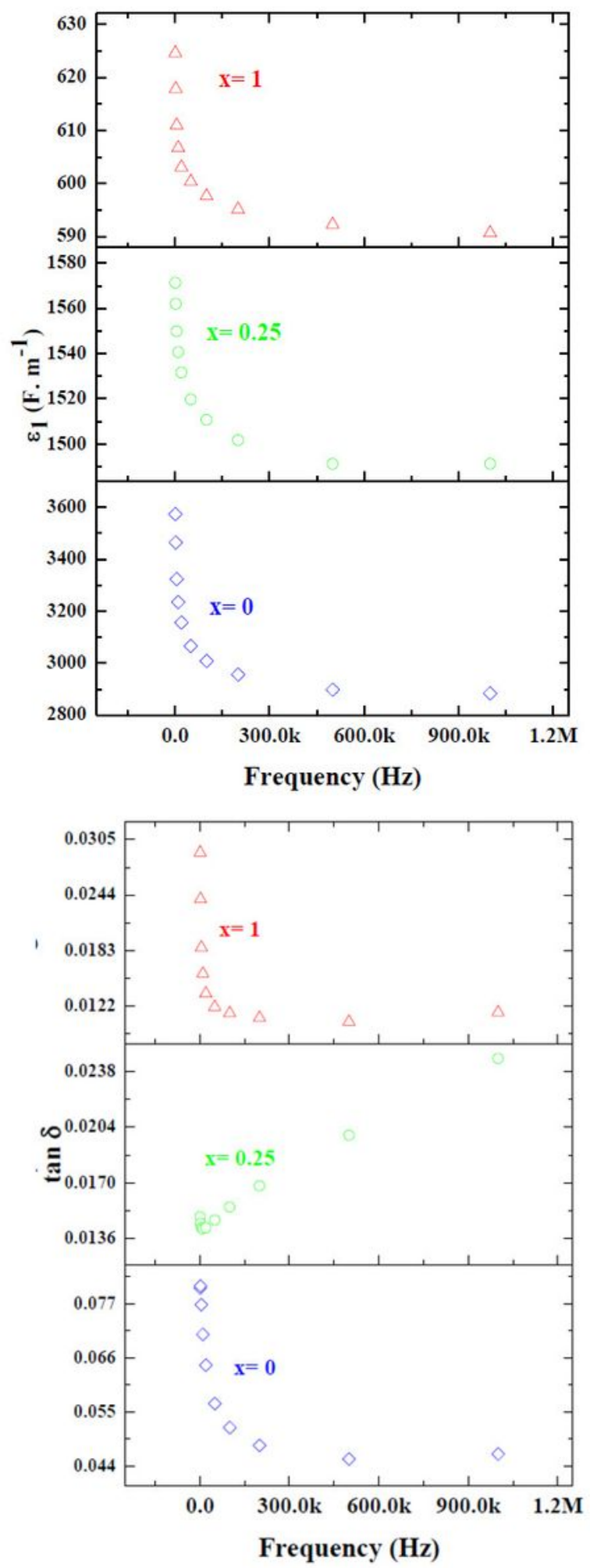

Figure 7

Dielectric constant and dielectric loss as functions of frequency for BCZT-xMn ceramics at T=Tm 


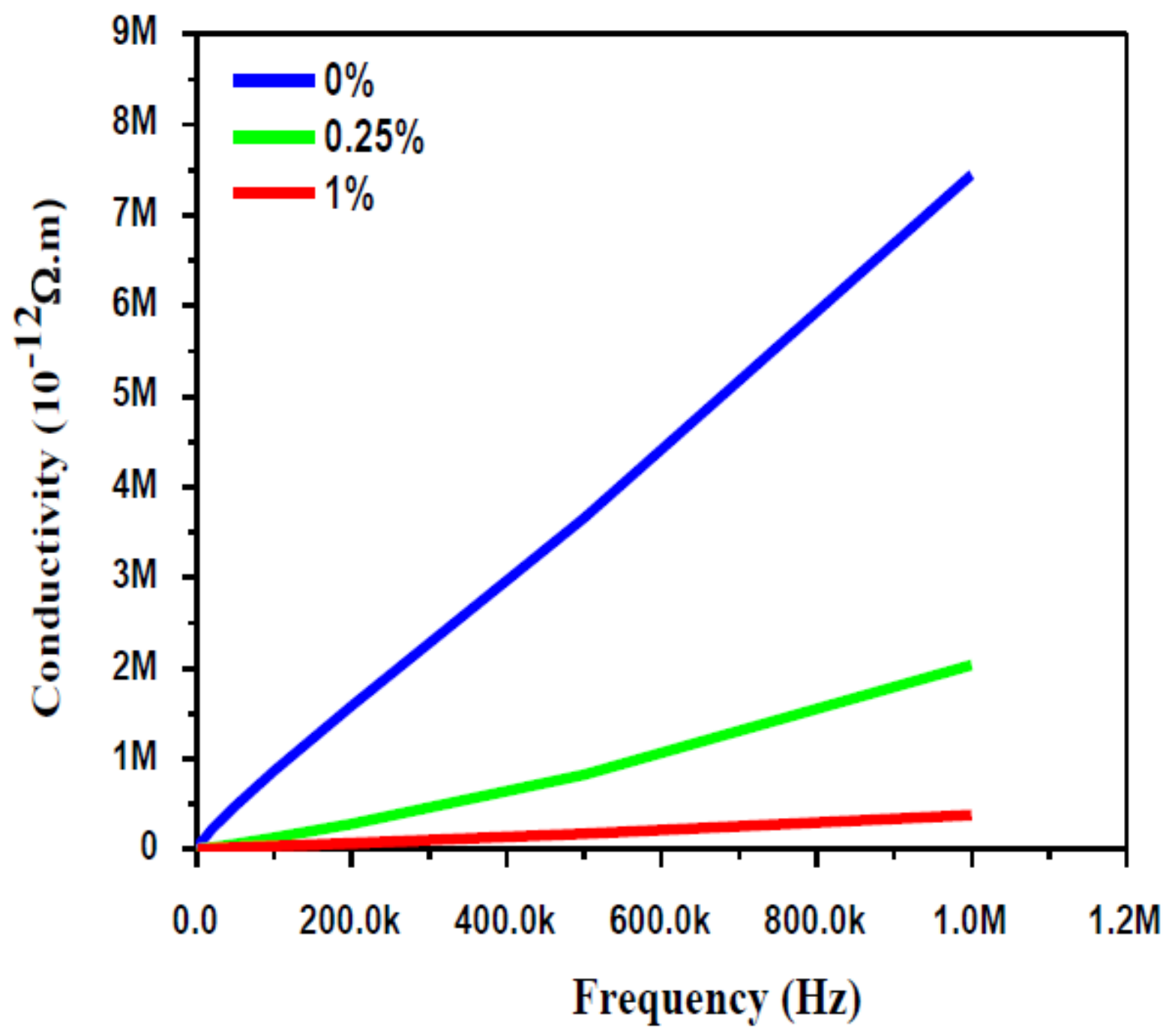

Figure 8

AC conductivity as function of frequency for Mn doped for BCZT-xMn (\%x=0, $0.25,1)$ at Tm. 